Research Article

\title{
Low-Frequency Performance Analysis of Semi-Active Cab's Hydraulic Mounts of an Off-Road Vibratory Roller
}

\author{
Vanliem Nguyen $\mathbb{D}^{1,2}$ Jianrun Zhang $\mathbb{D}^{3}{ }^{3}$ and Xiuzhi Yang ${ }^{1}$ \\ ${ }^{1}$ School of Mechanical and Electrical Engineering, Hubei Polytechnic University, Huangshi, China \\ ${ }^{2}$ Faculty of Automotive and Power Machinery Engineering, Thai Nguyen University of Technology, Thai Nguyen, Vietnam \\ ${ }^{3}$ School of Mechanical Engineering, Southeast University, Nanjing, China
}

Correspondence should be addressed to Vanliem Nguyen; xuanliem712@gmail.com

Received 15 November 2018; Revised 31 December 2018; Accepted 27 January 2019; Published 17 April 2019

Academic Editor: Gabriele Cazzulani

Copyright (c) 2019 Vanliem Nguyen et al. This is an open access article distributed under the Creative Commons Attribution License, which permits unrestricted use, distribution, and reproduction in any medium, provided the original work is properly cited.

\begin{abstract}
To improve the ride comfort of the off-road vibratory roller, the cab's hydraulic mounts were analyzed to prevent vibration sources transmitting to the cab. However, the cab's low-frequency shaking in the vertical direction and the direction of forward motion is still great. This study proposes an optimal fuzzy-PID control method for semi-active cab's hydraulic mounts based on an off-road vehicle roller dynamic model to analyze the low-frequency performance of semi-active cab's hydraulic mounts under the different operating conditions. In order to evaluate the ride comfort of the off-road vibratory roller with semi-active cab's hydraulic mounts, the power spectral density (PSD) and the weighted root mean square (RMS) of acceleration responses of the vertical driver's seat, cab's pitch, and roll vibrations in the low-frequency range are chosen as objective functions. Contrastive analysis of low-frequency vibration characteristics of the off-road vibratory roller with passive cab's hydraulic mounts, semi-active cab's hydraulic mounts without optimization, and semi-active cab's hydraulic mounts with optimization is, respectively, carried out. The research results show that the semi-active cab's hydraulic mounts with optimization have an obvious effect on mitigating the cab shaking and improving the ride comfort in comparison with passive cab's hydraulic mounts and semi-active cab's hydraulic mounts without optimization.
\end{abstract}

\section{Introduction}

The vibratory roller plays an important in the field of the construction project on roads, railways, airports, and so on. There is a combination of the static force of the vehicle self and the dynamic force of the vibratory drum yielded by an eccentric mass rotating around the drum axis to compact soil, asphalt, and other materials in its work process. Thus, the vehicle's vibration dynamics were mainly generated by the wheelsdeformable terrain interaction in the condition of the vehicle traveling and the drum/tyres-elastoplastic terrain interactions in the condition of the vehicle working [1-4]. The interaction model between the tyre and soft soil ground had been applied for researching the effect of soil deformation on off-road vehicle ride responses $[5,6]$. The dynamic pressuresinkage relationship of a smooth rigid wheel-terrain interaction model was also studied [7]. Besides, the effect of the random terrain surfaces on earth-moving machinery's ride comfort had been researched via the wheels-soil contact model $[6,8]$. All research results indicated that the vibration responses of interactive models were strongly affected by the off-road deformed terrains.

Consequently, the vibratory roller's ride comfort was researched via the interaction model between wheels and offroad terrain. The influence of design parameters of passive cab's rubber mounts (PRMs) on the ride dynamics of a soil compactor was studied via experiment and simulation [9], and the PRM's parameters were then optimized to improve the ride comfort [10]. The research results showed that the vibration responses of the vertical driver's seat and cab's pitch were greatly affected under various operating conditions. Because the low-frequency excitation arising from the wheels-terrain interaction is mostly transmitted to the cab and the driver's seat through PRM and seat's suspension, the vibration responses in 
the low-frequency range of $0.5-10 \mathrm{~Hz}$ caused by terrain surface roughness can lead to the main risk factors which seriously affect the driver's mental and physical health [11]. Therefore, the PRM is difficult to satisfy the driver's ride comfort under the low-frequency excitation region of off-road terrain.

The vibratory roller cab's isolation system is one of the most important factors to improve the driver's ride comfort. A 3D nonlinear dynamic model of an off-road vibratory roller equipped with three different cab's isolation mounts including the PRM, the passive hydraulic mounts (PHMs), and the pneumatic mounts was studied via the simulation and experimental investigations to investigate the vehicle's ride comfort in a low-frequency region [1]. The results showed that the low-frequency and high-stiffness characteristics of the PHM have a good effect on isolating lowfrequency vibration transmitted and controlling the cab shaking of the vibratory roller. However, the vertical driver's seat and cab's pitch vibrations were still great under operating conditions according to ISO 2631-1:1997 [12]. Therefore, research and control of the semi-active cab's hydraulic mounts (SHMs) of the vibratory roller to enhance the ride comfort is necessary.

Nowadays, the combined control methods, such as the neural-PID control, fuzzy-PID control, and integrated fuzzy-wheelbase preview control [13-15], were strongly developed for controlling the magnetorheological fluid of the semi-active suspension systems [16-18]. In order to enhance the control performance, the optimal control methods, such as neuro-fuzzy control with the fuzzy rules optimized by the genetic algorithm [19], fuzzy-PID control with the control rules optimized by cultural algorithm [20], and fuzzy-skyhook control using the multiobjective microgenetic algorithm [21], were also successfully applied. The research results showed that the optimal control methods were better than without optimization. However, all the above research studies mainly investigate the performance of the control methods; thus, the quarter car models are mostly used for all research studies. In addition, the above combined control methods have not yet been considered and applied for the SHM of the vibratory roller. Therefore, researching an optimal control method for the SHM to enhance further the off-road vibratory roller's ride comfort is necessary.

In this study, based on a three-dimensional nonlinear dynamic model of the off-road vibratory roller equipped with PHM [1], an SHM using the magnetorheological fluid with adjustable damping is then developed. An optimal fuzzy-PID control method in which the fuzzy control rules optimized by the genetic algorithm program is applied to optimize the control force of the SHM. The performance of SHM with optimization for the ride comfort and the health of the driver is then evaluated through the power spectral density (PSD) and weighted root mean square (RMS) acceleration responses of the vertical driver's seat, cab's pitch, and roll vibrations in both the frequency and time domains under actual operating conditions of the off-road vibratory roller.

The innovation in this paper is that an 11-DOF vehicle dynamics model which can fully reflect the pitch and roll of the cab is concerned under the various operating conditions.
A new optimal method of the fuzzy control rules based on the genetic algorithm, which is known as a multiobjective optimal algorithm with wide search range and short search time, is successfully developed and applied for the optimal fuzzy-PID controller. The two evaluation methods including the evaluation method of the vibration effect to the driver's ride comfort via the weighted RMS acceleration response in the time region and the evaluation method of the vibration effect to the health and safety of the driver via the PSD acceleration responses in the low-frequency region are carried out. The vibration responses of the vibratory roller under low-frequency excitation of the off-road terrain ground, especially the pitch and roll vibration response of the cab with PHM, SHM without optimization, and SHM with optimization are, respectively, simulated and analyzed. The results show that the low-frequency and high-stiffness characteristics of SHM with optimization have a good effect on isolating low-frequency vibration transmitted and controlling the cab shaking of the vibratory roller.

\section{Vibratory Roller Dynamic Models}

2.1. Modeling of the Off-Road Vibratory Roller Dynamic. Based on a three-dimensional nonlinear dynamic model of the off-road vibratory roller [1], as shown in Figure 1(a), the basic structure of the vibratory roller consists of the rigid drum/tires, the front/rear vehicle frame, the cab, and the seat. The cab is connected with the rear frame via the cab's isolation mounts which contain PRM, PHM, or SHM, as shown in Figures 1(b)-1(d), respectively.

A three-dimensional nonlinear dynamic model with eleven-DOF of a single drum vibratory roller and the cab's isolation mount models are built as in Figures 2(a) and 2(b).

In Figure $2(\mathrm{a}), z_{\mathrm{s}}$ represents the vertical motion at the driver's seat. $z_{\mathcal{c}}, \phi_{\mathrm{c}}$, and $\theta_{\mathrm{c}}$ are the vertical, the pitch, and the roll motions at the cab, respectively, and those are described as $z_{\mathrm{rf}}, \phi_{\mathrm{rf}}$, and $\theta_{\mathrm{rf}}$ at the rear vehicle frame. The vertical and roll motions of the front frame and the drum are described as $z_{\mathrm{ff}}, \theta_{\mathrm{ff}}$ and $z_{\mathrm{d}}, \theta_{\mathrm{d}} . z_{\mathrm{sej}}$ and $z_{\mathrm{t} j}$ are the vertical motion of the deformable terrain under the drum and the tyres. The mass of the driver, the cab, the front frame, the engine, the rear frame, and the roller drum is described as $m_{\mathrm{s}}, m_{\mathrm{c}}, m_{\mathrm{ff}}, m_{\mathrm{rf}}$, and $m_{\mathrm{d}}$, respectively. $F_{\mathrm{c} i}$ is the vertical dynamic forces generated by the cab's isolation mounts $(i=1-4) \cdot q_{\mathrm{t} j}$ and $q_{\mathrm{d} j}$ are the off-road terrain roughness surface at tyres and drum contacts.

Based on the dynamic model of the vibratory roller and off-road terrains interaction, as shown in Figure 2(a), and the motion equations of the driver's seat, cab, front/rear vehicle frame, and wheels-deformable terrains interaction [1], the motion equations of the off-road vibratory roller can be represented in the matrix form as follows:

$$
[\mathbf{M}]\{\ddot{\mathbf{Z}}\}+[\mathbf{C}]\{\dot{\mathbf{Z}}\}+[\mathbf{K}]\{\mathbf{Z}\}=\{\mathbf{F}(t)\},
$$

where $[\mathbf{M}],[\mathbf{C}]$, and $[\mathbf{K}]$ are $(m \times m)$ mass, damping, and stiffness matrices, respectively, $\{\mathbf{Z}\}$ is the $(m \times 1)$ displacement vector, $\{\mathbf{F}(t)\}$ is the $(m \times 1)$ exciting force vector, and $m$ is the number of DOF $(m=11)$. 


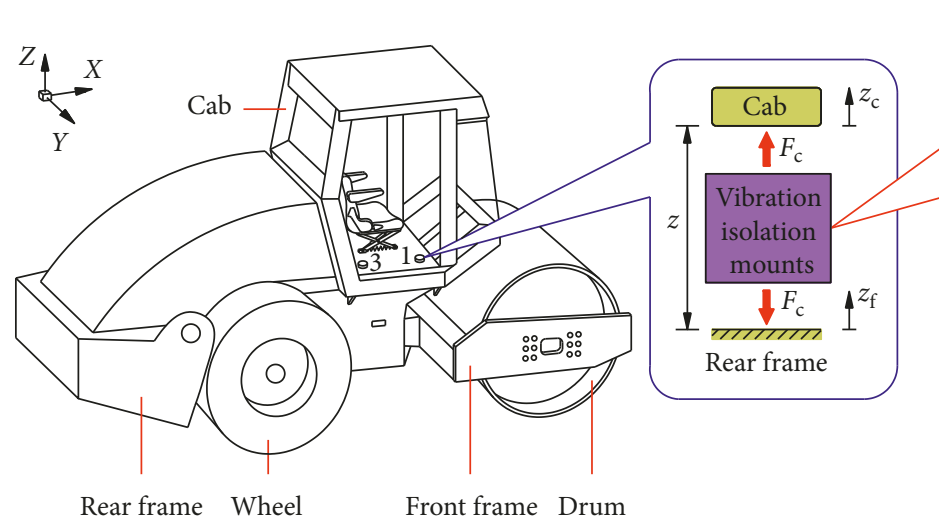

(a)

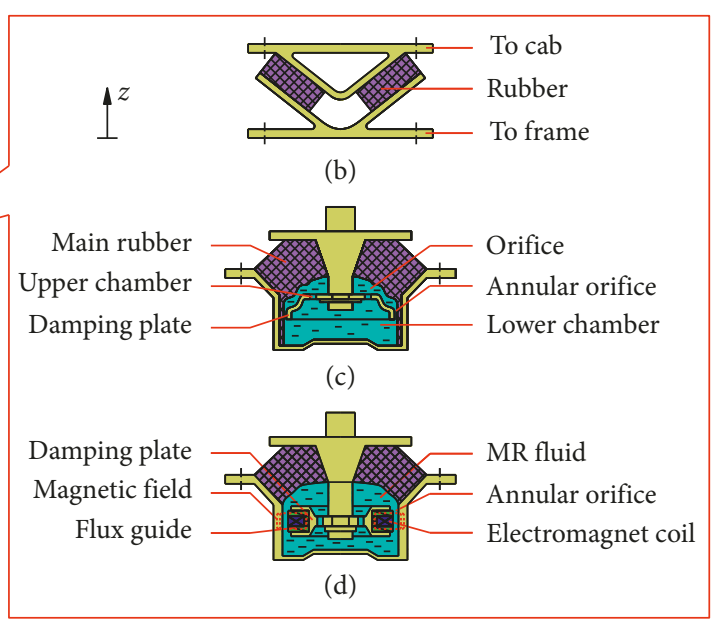

(d)

FIGURE 1: Schematic of vibratory roller with different cab's isolation mounts. (a) Single drum vibratory roller. (b) Passive rubber mount. (c) Passive hydraulic mount. (d) Semi-active hydraulic mount.

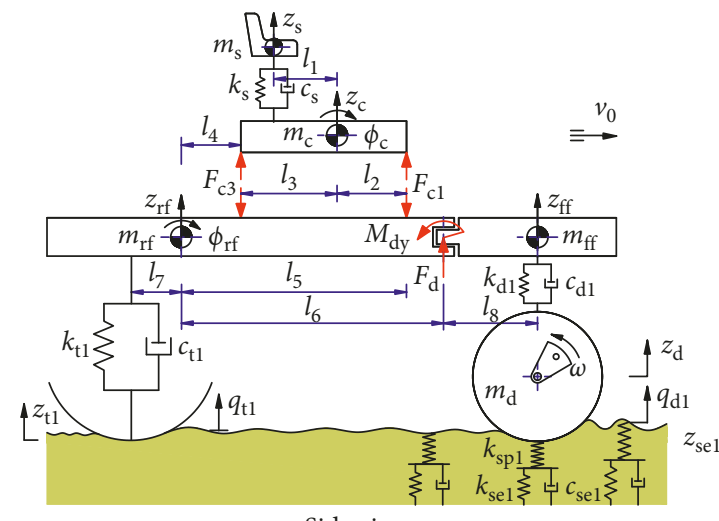

Side view

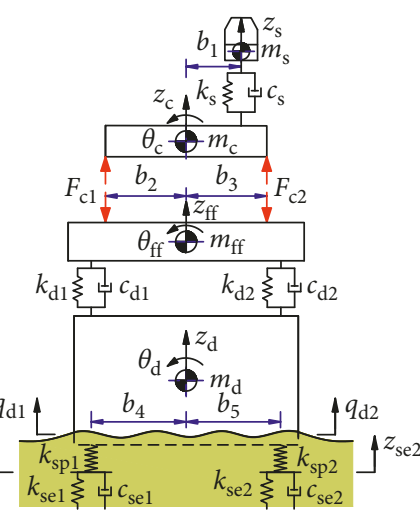

Front view

(a)

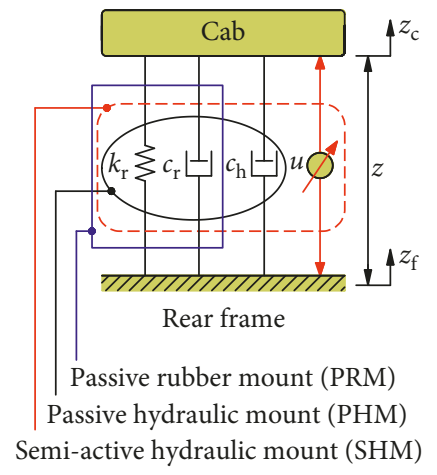

(b)

FIGURE 2: Lumped parameter model of the vibratory roller and different cab's isolation mounts. (a) Vibratory roller dynamic model. (b) Cab's isolation mount model.

2.2. Mathematical Model for the Cab's Isolation Mounts. Both the PRM and the PHM, as plotted in Figures 1(b) and $1(c)$, and their lumped parameter models described as in Figure 2(b) were studied via the simulation and experiment [1]. Herein, $k_{\mathrm{r}}$ and $c_{\mathrm{r}}$ are linear stiffness and damping coefficient of the main rubber mount, and a liquid damping force $f_{\mathrm{d}}=c_{\mathrm{h}}|\dot{z}| \dot{z}$ is expressed as the damping characteristic of a quadratic nonlinearity, in which $c_{\mathrm{h}}$ is the damping constant of the hydraulic mount.

In addition, a new model of SHM for the vibratory roller based on the PHM is proposed in this study. The basic structure of an SHM includes a main rubber, a damping plate driven by the bolt, and a closed chamber filled with the fluid. However, the fluid used in the closed chamber is a 
magnetorheological (MR) fluid with adjustable damping [16-18]. The damping plate of the SHM is equipped with an electromagnet coil and a flux guide. When the coil current is changing, a magnetic field in the flux guide is also being transformed; thus, the viscosity of MR fluid in the annular orifice is simultaneously changing. The result is that the vibration damping can be adjusted according to the different road surfaces. MR fluid flows in the upper-lower chamber are also derived by the transfer of damping plate through the annular orifice and the orifices, as seen in Figure $1(\mathrm{~d})$. The lumped parameter model of SHM is also represented by a linear stiffness $k_{\mathrm{r}}$ and damping $c_{\mathrm{r}}$ coefficients of the main rubber and a semi-active damping force of hydraulic mount, $f_{\mathrm{d}}=c_{\mathrm{h}}|\dot{z}| \dot{z}+u$. Herein, $u$ is an active damping force of MR fluid which is controlled by an optimal fuzzy-PID controller, as shown in Figure 2(b).

The corresponding dynamic force at mount $i$ of the cab's isolation mounts in the vertical direction is given by

$$
\begin{aligned}
& F_{\mathrm{c} i}=k_{\mathrm{r} i}\left(z_{\mathrm{c} i}-z_{\mathrm{rf} i}\right)+c_{\mathrm{r} i}\left(\dot{z}_{\mathrm{c} i}-\dot{z}_{\mathrm{rf} i}\right)+f_{\mathrm{d} i}, \\
& f_{\mathrm{d} i}= \begin{cases}0, & \text { with PRM, } \\
c_{\mathrm{h} i}\left|\dot{z}_{\mathrm{c} i}-\dot{z}_{\mathrm{rf} i}\right|\left(\dot{z}_{\mathrm{c} i}-\dot{z}_{\mathrm{rf} i}\right), & \text { with PHM, } \\
c_{\mathrm{h} i}\left|\dot{z}_{\mathrm{c} i}-\dot{z}_{\mathrm{rf} i}\right|\left(\dot{z}_{\mathrm{c} i}-\dot{z}_{\mathrm{rf} i}\right)+u_{i}, & \text { with SHM, }\end{cases} \\
& z_{\mathrm{c} i}=z_{\mathrm{c}}+(-1)^{\alpha} l_{\alpha+1} \phi_{\mathrm{c}}+(-1)^{i} b_{\delta} \theta_{\mathrm{c}}, \\
& z_{\mathrm{rf} i}=z_{\mathrm{rf}}-l_{v} \phi_{\mathrm{rf}}+(-1)^{i} b_{\delta} \theta_{\mathrm{rf}}, \\
& \dot{z}_{\mathrm{c} i}=\dot{z}_{\mathrm{c}}+(-1)^{\alpha} l_{\alpha+1} \dot{\phi}_{\mathrm{c}}+(-1)^{i} b_{\delta} \dot{\theta}_{\mathrm{c}}, \\
& \dot{z}_{\mathrm{rf} i}=\dot{z}_{\mathrm{rf}}-l_{v} \dot{\phi}_{\mathrm{rf}}+(-1)^{i} b_{\delta} \dot{\theta}_{\mathrm{rf}},
\end{aligned}
$$

where $z_{\mathrm{c} i}, z_{\mathrm{rf} i}$ and $\dot{z}_{\mathrm{c} i}, \dot{z}_{\mathrm{rf} i}$ are the displacements and the velocities of the cab frame and the rear frame at mount $i$ of the isolation mounts. When $i=1-2$ then $\alpha=1, v=5$, and $\delta=i+1$; when $i=3-4$ then $\alpha=2, v=4$, and $\delta=i-1$.

\subsection{Random Excitation of the Off-Road Terrain Surface.} In actual operating conditions, the excitation forces of the vibratory roller are strongly affected by the rough terrain surfaces apart from wheels-deformable terrain interactions. The terrain behaviour under wheel-soil contact is nonlinear. Thus, the off-road vibratory rollers must be studied in the frequency domain apart from the traditional time domain to analyze the influence of excitation on the ride response. Offroad terrain surface in the frequency domain is calculated via the PSD value [6]. The spatial PSD of the road surface profile, $S(\Omega)$, is described as a function of the spatial frequency $\Omega$ (cycle $\cdot \mathrm{m}^{-1}$ ). The spectral density of off-road terrain is thus written in accordance with ISO proposal [22] over the different spatial frequency ranges by

$$
S(\Omega)=S\left(\Omega_{0}\right)\left(\frac{\Omega}{\Omega_{0}}\right)^{-w_{0}},
$$

where $w_{0}=3$ for $\Omega \leq \Omega_{0}$ and $w_{0}=2.25$ for $\Omega>\Omega_{0}$; the value $S\left(\Omega_{0}\right)$ provides a measure for the random terrain with the reference spatial frequency $\Omega_{0}=1 / 2 \pi$ cycle $\cdot \mathrm{m}^{-1}$.
More specifically, assuming the vehicle moves with a constant speed $v_{0}$, the off-road terrain irregularities in the time domain can then be simulated by the series

$$
q(t)=\sum_{i=1}^{N} s_{i} \sin \left(i \Delta \omega t+\phi_{i}\right),
$$

where $N$ is the number of intervals and $s_{i}=\sqrt{2 S(i \Delta n) \Delta n}$ is the amplitude of each the excitation harmonic in which $S$ is the target spectral density. $\Delta n=2 \pi / L$, and $L$ is the length of the road segment. $\varphi_{i}$ is a random phase uniformly distributed between 0 and $2 \pi$, and $\Delta \omega=\Delta n v_{0}$ is the fundamental temporal frequency. Mitschke [23] extended the spectral density ranges for the unpaved off-road classifications apart from the traditional asphalt road classifications, including the classification ranges from good to very poor, and the desired terrain roughness can be yielded by choosing a value in the spectral density ranges.

In order to develop an off-road terrain roughness input closing to the actual terrain condition, the simulation parameters used for generating the time domain of a rough terrain surface, as shown in Figure 3(a), are a type of poor off-road classification with $v_{0}=1.67 \mathrm{~m} \cdot \mathrm{s}^{-1}, L=84 \mathrm{~m}$, $\Delta t=0.005 \mathrm{~s}, w_{0}=2.14$, and $S\left(\Omega_{0}\right)=3782.5 \times 10^{-6} \mathrm{~m}^{3} \cdot$ cycle $^{-1}$. Its spectral density obtained from the time domain is also depicted in Figure 3(b). The frequency region of the input signal is mainly below $10 \mathrm{~Hz}$.

2.4. Experimental Model Results. In order to validate the accuracy of the mathematical model of the off-road vibratory roller, experiments and simulations were carried out with cab's isolation systems when the vehicle moved and compacted at a speed $v_{0}=0.83 \mathrm{~m} \cdot \mathrm{s}^{-1}$ on a poor elastoplastic terrain surface at the excitation frequency, $28 \mathrm{~Hz}$, of the drum [1]. The comparison results are shown in Figure 4. With PRM, as plotted in Figures 4(a)-4(c), comparisons of simulation and experimental results of the PSD acceleration responses are show that the simulation results almost agree with the tests as to the frequency of the various peaks in the responses and the trend. In addition, the weighted RMS values of the vertical driver's seat, cab's pitch, and roll vibrations of PRM, as shown in Figure 4(d), are deviated small by $10.20 \%, 11.21 \%$, and $12.67 \%$ in comparison with the measured values. It implies that the mathematical model of the vibratory roller is the accurate and feasible model.

In addition, simulation results with $\mathrm{PHM}$ showed that both PSD acceleration responses and the weighted RMS values of the vertical driver's seat, cab's pitch, and roll vibrations are greatly reduced, and the PHM has almost no effect on the resonance frequencies in comparison with PRM under the various operating conditions. Therefore, the model of the off-road vibratory roller using PHM not only enhances the vehicle's ride comfort but also provides the accurate and feasible model for low-frequency performance analysis of the semi-active cab's hydraulic mounts (SHMs). 


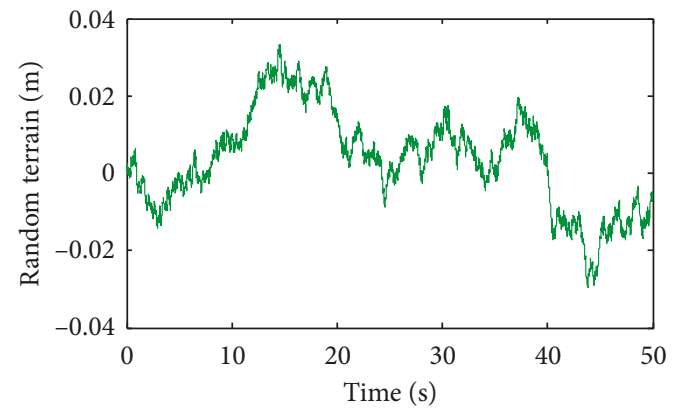

_ Off-road terrain roughness

(a)

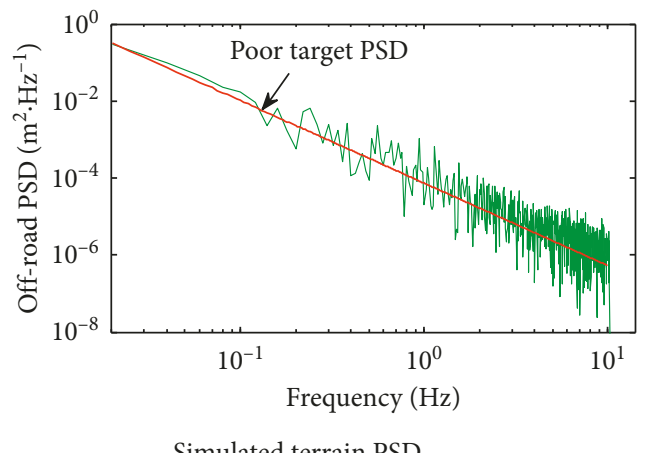

(b)

Figure 3: Generation of the off-road terrain roughness according to unpaved off-road classification. (a) Off-road terrain profile. (b) Spectral densities.
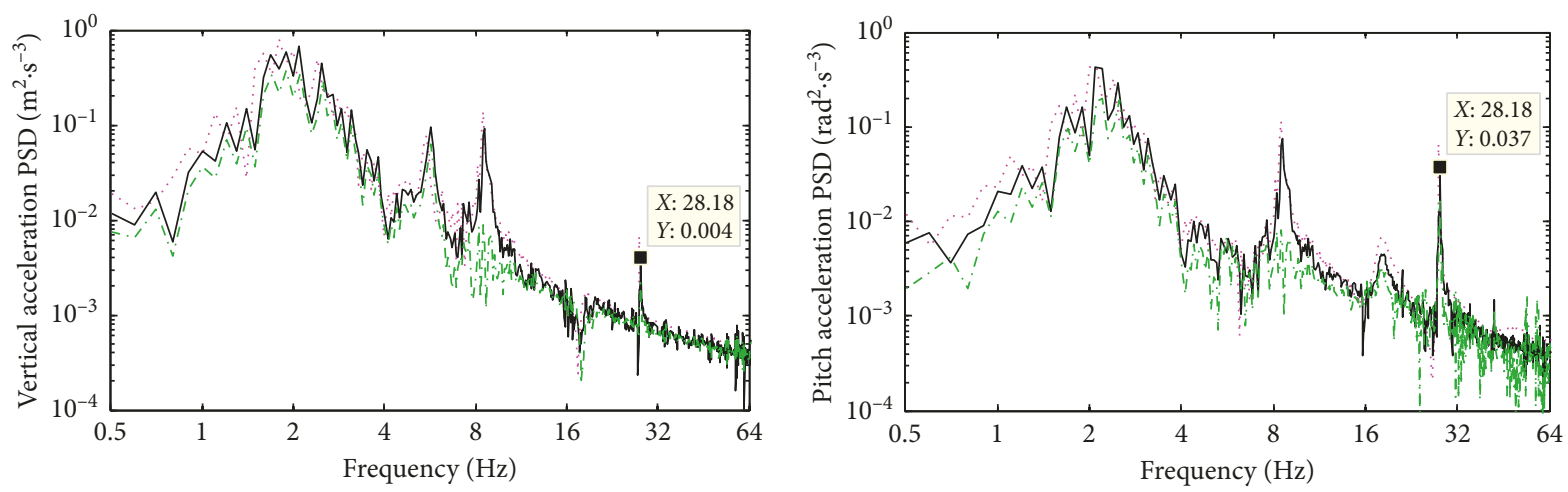

.... Experiment with PRM

— Simulation with PRM

-. - Simulation with PHM

(a)

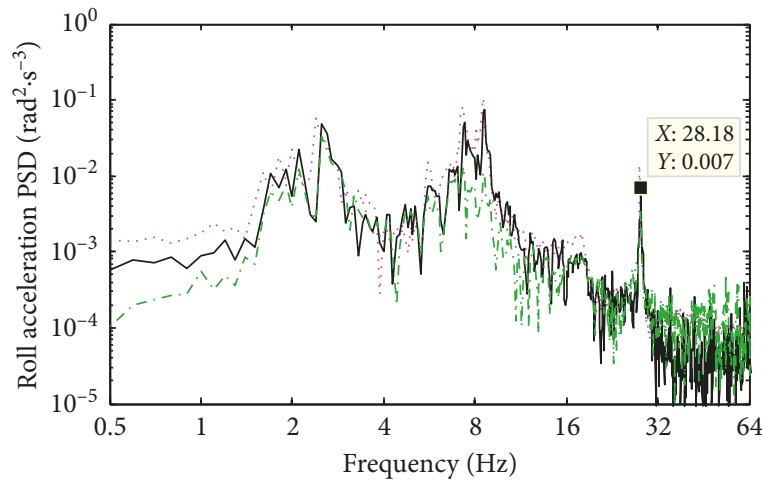

Experiment with PRM

Experiment with PRM

- Simulation with PRM

_. - Simulation with PHM

(b)

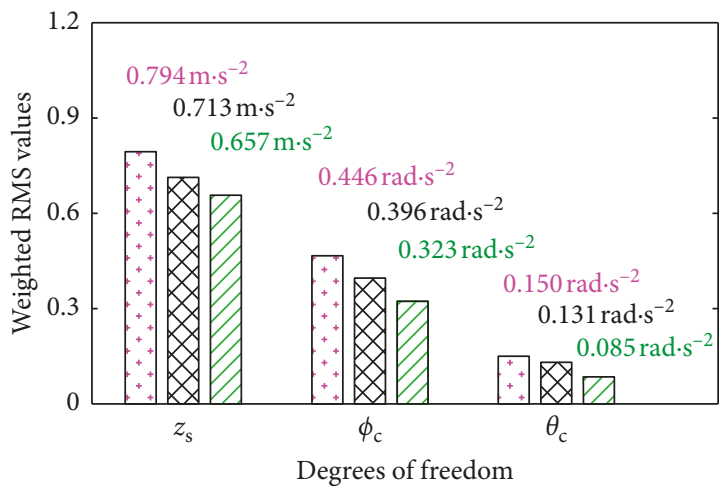

$+{ }_{+\infty}^{+}$Experiment with PRM

$\triangle$ Simulation with PRM

$\square$ Simulation with PHM

(d)

FIgURE 4: The experimental and simulation results under an excitation frequency $28 \mathrm{~Hz}$ of the drum [1]. (a) PSD acceleration response of the vertical driver's seat. (b) PSD acceleration response of the cab's pitch angle. (c) PSD acceleration response of the cab's roll angle. (d) Weighted RMS values of the driver's seat and the cab. 


\section{Design of the Optimal Fuzzy-PID Controller}

3.1. Modeling of the Optimal Fuzzy-PID Control. The PID control is one of the controllers with not only a simple structure but also robust performance, and it is generally used in industrial process control. However, the performance of PID control depends on the appropriate selection of the PID's parameters. The well-known Ziegler-Nichols technique has been used to choose the PID's parameters. However, it is only efficient when the system works at the designed operating condition. Contrariwise, the fuzzy logic control (FLC) does not depend on the designed operating condition; it only depends on the appropriate selection of the fuzzy inference system (FIS). However, the shortcomings of FLC are low precision and stability. In order to avoid shortcomings of both FLC and PID control, fuzzy-PID control had been developed $[18,20,24]$. In this study, to enhance the control performance of fuzzy-PID control (FPC), the control rules in FIS optimized via the genetic algorithm (GA) program are then developed and applied for the FPC's optimization.

In the cab's isolation mounts, there are four SHMs which should be separately controlled; thus, four optimal fuzzyPID controls should be designed. However, the design process of these controls is the same. Therefore, a specific of the optimal FPC is designed to control the active damping force of MR fluid. The model of the optimal FPC for SHM is depicted in Figure 5(a).

In Figure 5(a), fuzzy-PID control includes two inputs and three outputs in which 2 inputs denoted by $E$ and EC are the vertical displacement error $(E)$ and the vertical velocity error (EC) of the cab frame, and 3 outputs denoted by $K_{\mathrm{p}}^{\prime}, K_{\mathrm{i}}^{\prime}$, and $K_{\mathrm{d}}^{\prime}$ are the proportionality factors, respectively. The proportional, integral, and derivative parameters in PID control are defined by $K_{\mathrm{p}}, K_{\mathrm{i}}$, and $K_{\mathrm{d}}$ which can be automatically tuned and depend on the parameters $K_{\mathrm{p}}^{\prime}, K_{\mathrm{i}}^{\prime}$, and $K_{\mathrm{d}}^{\prime}$ of the FLC, and the actual control force of MR fluid $u(t)$ is decided by the PID control; the control force $f_{\mathrm{d}}$ of SHM is then used for subsystem of the vehicle. In order to enhance the further performance of the FPC, the GA program is used to optimize the control rules in FIS via the subsystem of the vehicle and the objective functions.

The force output of the PID control is given by

$$
u(t)=K_{p} e(t)+K_{i} \int_{0}^{t} e(t) d t+K_{d} \dot{e}(t),
$$

where $e(t)$ is the displacement error the cab frame.

The initial values of proportionality factors in equation (5) determined by the Ziegler-Nichols method via the subsystem model are $K_{\mathrm{p}}(0)=1985, K_{\mathrm{i}}(0)=18$, and $K_{\mathrm{d}}(0)=$ 1.2. In order to find the best values for $K_{\mathrm{p}}, K_{\mathrm{i}}$, and $K_{\mathrm{d}}$, we assume their variable ranges as $\left[K_{\mathrm{pmin}}, K_{\mathrm{pmax}}\right]$, [ $\left.K_{\mathrm{imin}}, K_{\mathrm{imax}}\right]$, and $\left[K_{\mathrm{dmin}}, K_{\mathrm{dmax}}\right]$, respectively. Thus, based on the initial values, the range of each parameter is chosen by $K_{\mathrm{p}} \in[100$, $2500], K_{\mathrm{i}} \in[1,100]$, and $K_{\mathrm{d}} \in[0.1,10]$.

The next is a design of the FLC. The basic fuzzy control consists of the following major parts: fuzzification interface, FIS, and defuzzification interface. First, the crisp values in fuzzification are transformed into linguistic variables, FIS is then used by control rules in accordance with inference rules, and finally, the linguistic variables are transformed back to crisp values through defuzzification for use by the physical plant [25]. Therefore, the FPC can be designed in three steps below:

(i) Choosing the fuzzy control input-output: two input variables $\mathrm{E}$ and $\mathrm{EC}$ belong to $[-0.25,0.25]$. Besides, three output variables $K_{\mathrm{p}}^{\prime}, K_{\mathrm{i}}^{\prime}$, and $K_{\mathrm{d}}^{\prime}$ are calibrated over the interval $[0,1]$ as follows [24]:

$$
\begin{gathered}
K_{p}^{\prime}=\frac{K_{p}-K_{p \text { min }}}{K_{p \text { max }}-K_{p \text { min }}}, \\
K_{i}^{\prime}=\frac{K_{i}-K_{i \text { min }}}{K_{i \text { max }}-K_{i \text { min }}}, \\
K_{d}^{\prime}=\frac{K_{d}-K_{d \text { min }}}{K_{d \text { max }}-K_{d \text { min }}} .
\end{gathered}
$$

Hence, the input values in equation (5) are, respectively, $K_{\mathrm{p}}=2400 K_{\mathrm{p}}^{\prime}+100, K_{\mathrm{i}}=99 K_{\mathrm{i}}^{\prime}+1$, and $K_{\mathrm{d}}=9.9 K_{\mathrm{d}}^{\prime}+0.1$.

The linguistic variables of two inputs are defined by the positive big $(\mathrm{PB})$, positive small (PS), zero ( $\mathrm{ZO})$, negative small (NS), and negative big (NB). Besides, the linguistic variables of three outputs are also defined as small $(S)$, medium small (MS), medium $(M)$, medium big $(\mathrm{MB})$, and big $(B)$, respectively.

(ii) Membership function: the shape of membership functions of input-output variables is used by the triangular function, and its degree of membership is between 0 and 1, as shown in Figure 5(b).

(iii) The FIS's rules: the initial control rules are given by the designer's knowledge and experience as follows:

(1) If $E$ is NB and EC is NB, then $K_{\mathrm{p}}^{\prime}$ is MS, $K_{\mathrm{i}}^{\prime}$ is S, and $K_{\mathrm{d}}^{\prime}$ is $S$

(2) If $E$ is NB and EC is NS, then $K_{\mathrm{p}}^{\prime}$ is $M, K_{\mathrm{i}}^{\prime}$ is MS, and $K_{\mathrm{d}}^{\prime}$ is $S$

$\ldots$

(25) If $E$ is $\mathrm{PB}$ and $\mathrm{EC}$ is $\mathrm{PB}$, then $K_{\mathrm{p}}^{\prime}$ is $B, K_{\mathrm{i}}^{\prime}$ is $\mathrm{MB}$, and $K_{\mathrm{d}}^{\prime}$ is $\mathrm{MB}$

where FIS is selected by the minimum function and the centroid method of Mamdani and Assilian [25], and the above control rules are then optimized by GA program through the subsystem model.

\subsection{Optimization of the Control Rules Based on the GA Program}

3.2.1. GA Program. GA is an optimization method based on principles of natural selection. It seeks the maximum or the minimum values of one or more objective functions using computational techniques motivated by biological reproduction. Therefore, GA is defined as finding a vector of decisive variables that satisfies constraints to give acceptable values to all objective functions [26,27], and it can be written as follows: 


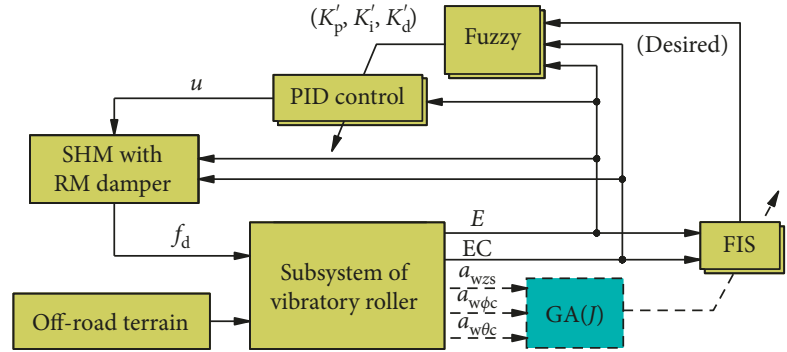

(a)

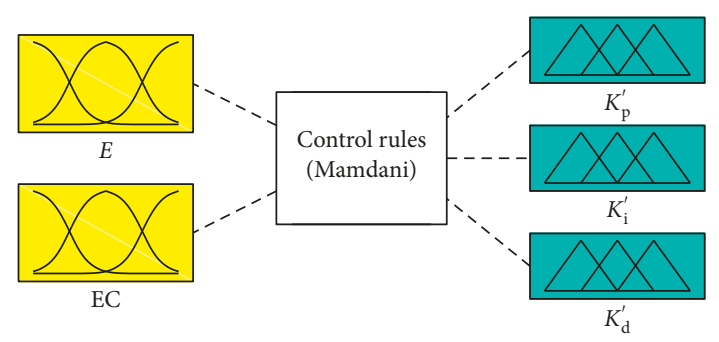

(b)

FIGURE 5: Structure of the vehicle model with SHM. (a) Optimal fuzzy-PID control model. (b) FLC control.

Find the vector $x=\left[x_{1}, x_{2}, \ldots, x_{n}\right]^{T}$ to optimize

$$
\begin{aligned}
F(x) & =\left[f_{1}(x), f_{2}(x), \ldots, f_{n}(x)\right]^{T}, \\
\text { subject to } g_{i}(x) & \leq 0, \quad i=1,2, \ldots, p, \\
h_{j}(x) & =0, \quad j=1,2, \ldots, q,
\end{aligned}
$$

where $F(x)$ is the vector of objective functions, which must be either maximized or minimized, and $p$ and $q$ are numbers of inequality constraints and equality constraints.

GA is structured into the following steps: encoding, population initialization, fitness evaluation, parent selection, genetic operations (crossover and mutate), and termination criterion. The flow chart of the GA program for SHM is built in Figure 6.

\subsubsection{Application of GA Program to Optimize the Control} Rules. The goal main of GA is to seek the optimal control rules in FIS to get the minimum values of the weighted RMS acceleration responses of the vertical driver's seat, cab's pitch, and roll vibrations via the subsystem model in Figure 5(a). Therefore, GA's structure is built as follows:

(i) Encoding mechanism and initial population: in “(iii) The FIS's rules," there are 25 control rules that contain a total of 75 elements. The 75 elements are then connected into a string of numbers as a chromosome which is regarded as a vector. Encoding mechanism can shorten the chromosome length of the individuals in population space to enhance the running speed and to reduce the searching space of the algorithm program. Thus, the linguistic variables of two inputs ( $E$ and EC) are encoded by the numbers as [NB, NS, ZO, PS, PB] = $[0,1,2,3,4]=\left[a_{j}\right]_{1 \times 5}$, and the linguistic variables of three outputs $\left(K_{\mathrm{p}}^{\prime}, K_{\mathrm{i}}^{\prime}\right.$, and $\left.K_{\mathrm{d}}^{\prime}\right)$ are encoded by the numbers as $[S, \mathrm{MS}, M, \mathrm{MB}, B]=[5,6,7,8,9]=$ $\left[b_{j}\right]_{1 \times 5}$. Besides, the individuals in the initial population are randomly generated. For each gene, the value of that gene is also selected as a random positive integer in the range of $0 \leq a_{j} \leq 4$ and $5 \leq b_{j} \leq 9$, and the size of the initial population is 100 .

(ii) Objective function and fitness value: the minimum values of the weighted RMS acceleration responses $\left(a_{\mathrm{wl}}\right)$ of the vertical driver's seat, cab's pitch, and roll vibrations are selected as objective functions in this

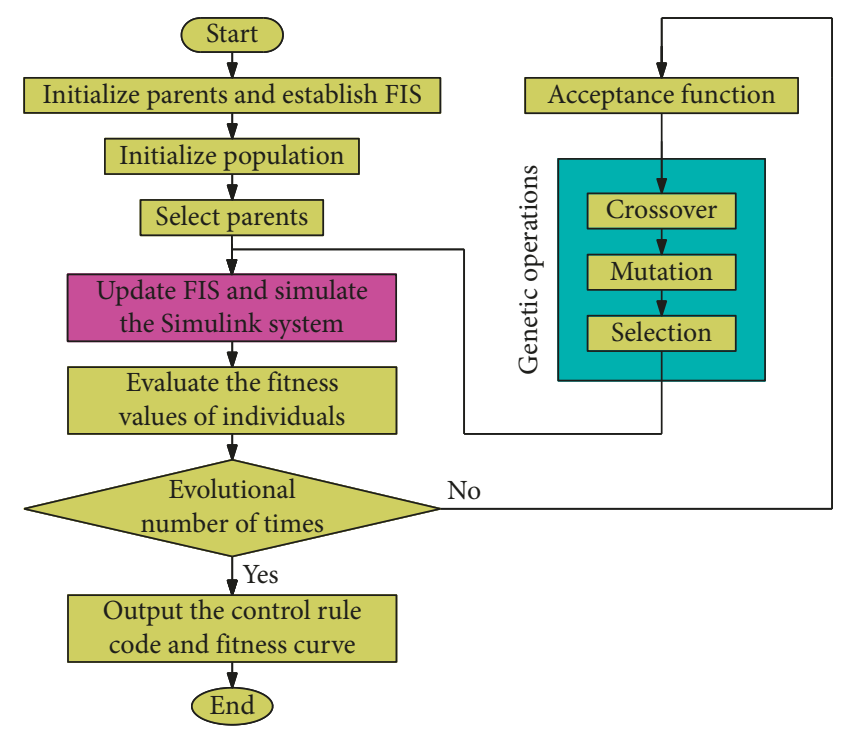

Figure 6: The flow chart of the GA program for SHM.

study. The expression of objective functions is written in equation (9). In order to find the minimum values of the weighted RMS acceleration responses, the fitness value $J$ is greatly simplified to calculate objective functions as follows $[20,27]$ :

$$
J=\frac{1}{\sum \alpha_{1} a_{\mathrm{wl}}^{2}},
$$

where subscript $l$ refers to the vertical driver's seat $\left(z_{\mathrm{s}}\right)$, cab's pitch $\left(\phi_{\mathrm{c}}\right)$, or cab's roll $\left(\theta_{\mathrm{c}}\right)$ vibrations and $\alpha_{1}$ is the scalar that weighted or percent of the weighted RMS values in $l$.

The individuals with the higher fitness value $J$ which is obtained via the subsystem model show that the obtained control rules in "(iii) The FIS's rules" are better. Therefore, the resultant individuals are updated before the evolution process ends, and the optimal individuals can be obtained.

(iii) Genetic operations: after establishing the initial population and selecting the parents. Genetic operations (including crossover and mutation) are then performed. Herein, crossover probability of 0.95 and mutation probability of 0.05 have been used in 200 
generations. Therefore, the arithmetic crossover is performed on $95 \%$ of the selected parents, whereby two children are created from the weighted sum of two parents, and children of the remaining 5\% of selected parents are exact copies of the parents. Crossover operation is performed until the population number is doubled. Then, each individual undergoes the mutation operation which is the process of randomly changing the values of genes in a chromosome with a probability of 0.05 . The mutation can create new genetic material into an existing individual and add diversity to the genetic characteristics of the population. Finally, through the fitness value $J$, only the optimal individuals are selected at the end of each generation to exist as the population of the next generation. For the termination criterion, the limitary generation is used; then, the resultant population is evaluated to determine convergence.

3.2.3. Optimal Result of the Control Rules. In order to seek the optimal control rules for the FPC, we assume that the vibratory roller travels on the deformable terrain at a constant speed $v_{0}=1.67 \mathrm{~m} \cdot \mathrm{s}^{-1}$, and off-road terrain excitation input $q(t)$ of the subsystem model is chosen as in Figure 3(a) with the simulation time of $10 \mathrm{~s}$. The scalar that weighted RMS values of the vertical driver's seat, cab's pitch, and roll vibrations are $\alpha_{z}=0.486, \alpha_{\phi}=0.449$, and $\alpha_{\theta}=0.065$, respectively, which are decided based on the percent of the weighted RMS value of the vertical driver's seat (48.6\%), cab's pitch (44.9\%), and cab's roll vibrations (6.5\%) with the weighted RMS values of the PHM in Table 1. The maximum generation is 200 .

The result in Figure 7 shows that the maximum fitness value $J$ is obtained from the evolutionary generation of 133 to the end. Therefore, the optimal individuals can be obtained at the generation of 133 . By recording, the optimal control rules in FIS are listed in Table 2. The optimal control rules are then used for the optimal FPC to simulate and analyze the low-frequency performance of semi-active cab's hydraulic mounts.

\section{Results and Discussion}

4.1. Evaluation Criteria. The performance of the vehicle suspension system is evaluated by three main indices in the time domain, including the ride comfort, working space, and road holding characteristics.

Among these three indices, the ride comfort performance evaluated via the weighted RMS acceleration response is considered to be the most important index [1]. In addition, in the international standard ISO 2631-1 [12], the PSD acceleration response is also applied to estimate the effect of vibration on the endurance limit of the human body in the frequency domain. It was suggested that a lowfrequency range of $4-10 \mathrm{~Hz}$ for the vertical and of $0.5-$ $2 \mathrm{~Hz}$ for the rotational vibrations seriously affected the driver's health and safety. In this study, the performance of SHM also is evaluated through both the PSD and the weighted RMS acceleration responses of the vertical driver's seat, cab's pitch, and roll vibrations in the frequency and time domains. Thus, the smaller PSD and weighted RMS values mean to be the better ability of the corresponding isolation mounts. The expression of RMS was given by

$$
a_{\mathrm{wl}}=\sqrt{\frac{1}{T} \int_{0}^{T}\left[\ddot{x}_{l}(t)\right]^{2} d t},
$$

where $\ddot{x}_{1}(t)$ is the acceleration response in the $l$ as a function of time and $T=50 \mathrm{~s}$ is the time of simulation.

\subsection{Control Performance When the Vehicle Travels on the} Deformable Terrain. In this study, the vehicle is assumed to be traveling on a terrain type of Grenville loam given by Wong [28] at a constant speed $v_{0}=1.67 \mathrm{~m} \cdot \mathrm{s}^{-1}$. The Grenville loam's parameters including $n=1.01, \quad k_{\mathrm{c}}=0.06 \times 10^{3} \mathrm{~N} \cdot \mathrm{m}^{-(n+1)}$, $k_{\varphi}=5880 \times 10^{3} \mathrm{~N} \cdot \mathrm{m}^{-(n+2)}, c=3.1 \times 10^{3} \mathrm{~Pa}, \varphi=29.8^{\circ}$, and its off-road terrain irregularity as in Figures 3(a) are the random excitation inputs of the simulating model. Simulations are then carried out to analyze the low-frequency performance of SHM based on the design parameters of a single drum vibratory roller [1].

A good cab's isolation system should be able to minimize its deflection and acceleration to enhance the driver's ride comfort. In addition, the driver's mental and physical health is affected not only by the acceleration responses in the time region but also by the PSD acceleration responses in the lowfrequency region [11]. Therefore, the maximum PSD and the weighted RMS values of the vertical driver's seat, cab pitch, and roll vibrations are, respectively, given to compare the low-frequency performance of SHM.

The simulation results of the PSD acceleration responses of the vertical driver's seat, cab's pitch, and roll vibrations are plotted in Figures 8(a)-8(c), respectively. In Figure 8, the resonance frequencies of PSD acceleration responses of the vertical driver's seat, cab's pitch, and roll vibrations with SHM without optimization and with optimization have not been changed in comparison with PHM. This can be due to the fact that stiffness coefficients of the cab's isolation system are unchanged and its damping control forces have almost no effect on the resonance frequencies. However, the maximum resonance peaks of the PSD acceleration responses are significantly transformed by the SHM.

The maximum resonance peaks of the PSD acceleration responses of the vertical driver's seat, cab's pitch, and roll vibrations of SHM without optimization are smaller than PHM. Meanwhile, the maximum resonance peaks of the PSD acceleration responses of SHM with optimization are the smallest. Especially in low-frequency below $4 \mathrm{~Hz}$, the maximum PSD values of the vertical driver's seat, cab's pitch, and roll vibrations of SHM with optimization are greatly reduced by $32.97 \%, 29.08 \%$, and $64.40 \%$ in comparison with PHM, respectively. This is due to the main impact of the semi-active damping force of hydraulic mount $f_{\mathrm{d}}=c_{\mathrm{h}}|\dot{z}| \dot{z}+u$. Therefore, the health of the driver can be clearly improved by SHM using the optimal fuzzy-PID controller.

The simulation results of the acceleration responses are also shown in Figures 9(a)-9(c). In Figure 9, we can see that 
TABLE 1: The weighted RMS acceleration responses on a deformable terrain.

\begin{tabular}{lcccc}
\hline Performance & PHM & SHM without optimization & SHM with optimization & SHM with optimization versus PHM (\%) \\
\hline$a_{\mathrm{w} z \mathrm{~s}}\left(\mathrm{~m} \cdot \mathrm{s}^{-2}\right)$ & 1.063 & 0.875 & 0.691 & 34.99 \\
$a_{\mathrm{w} \phi \mathrm{c}}\left(\mathrm{rad} \cdot \mathrm{s}^{-2}\right)$ & 0.982 & 0.810 & 0.564 & 42.56 \\
$a_{\mathrm{w} \theta \mathrm{c}}\left(\mathrm{rad} \cdot \mathrm{s}^{-2}\right)$ & 0.139 & 0.100 & 0.081 & 41.72 \\
\hline
\end{tabular}

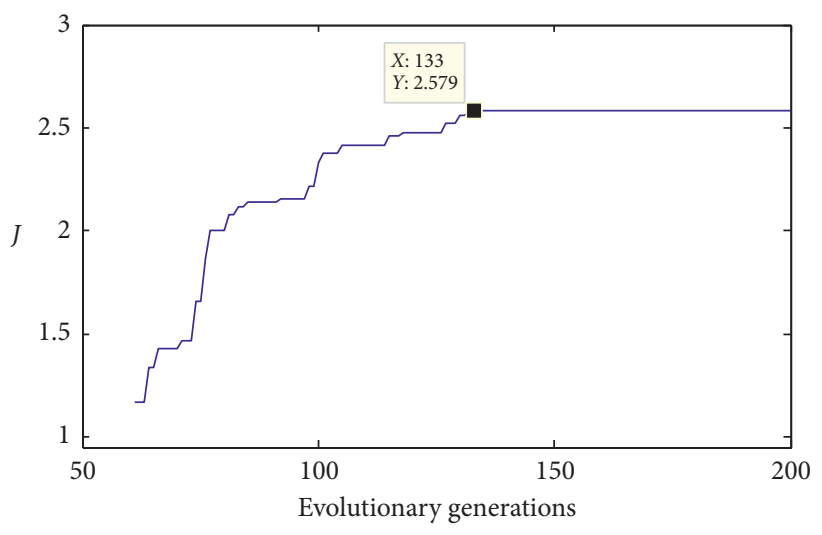

FIgURE 7: The curve of fitness value.

TABLE 2: Result of the optimal control rules.

\begin{tabular}{|c|c|c|c|c|c|c|c|c|c|c|c|c|c|c|c|}
\hline \multirow{3}{*}{ EC } & \multicolumn{15}{|c|}{$\mathrm{E}$} \\
\hline & & & $K_{\mathrm{p}}^{\prime}$ & & & & & $K_{\mathrm{i}}^{\prime}$ & & & & & $K_{\mathrm{d}}^{\prime}$ & & \\
\hline & NB & NS & $\mathrm{ZO}$ & PS & $\mathrm{PB}$ & NB & NS & $\mathrm{ZO}$ & PS & $\mathrm{PB}$ & $\mathrm{NB}$ & NS & $\mathrm{ZO}$ & PS & $\mathrm{PB}$ \\
\hline NB & $\mathrm{M}$ & MB & B & MS & S & $S$ & $S$ & $\mathrm{M}$ & MB & $S$ & $\mathrm{~S}$ & $\mathrm{M}$ & B & $\mathrm{MB}$ & B \\
\hline NS & MB & $\mathrm{M}$ & MS & $\mathrm{M}$ & MS & S & B & $\mathrm{MB}$ & MS & $\mathrm{M}$ & MS & $S$ & $\mathrm{M}$ & $\mathrm{M}$ & $S$ \\
\hline $\mathrm{ZO}$ & $\mathrm{M}$ & $\mathrm{S}$ & S & $S$ & $\mathrm{M}$ & MS & MS & S & $\mathrm{M}$ & $\mathrm{MB}$ & $\mathrm{M}$ & B & $\mathrm{S}$ & S & MS \\
\hline PS & MS & $\mathrm{M}$ & MS & $\mathrm{M}$ & B & MS & S & $\mathrm{M}$ & $\mathrm{MB}$ & S & $\mathrm{MB}$ & MS & S & MS & MS \\
\hline $\mathrm{PB}$ & S & MS & $\mathrm{M}$ & $\mathrm{MB}$ & $\mathrm{MB}$ & M & $\mathrm{M}$ & MS & S & $S$ & MS & B & S & S & $\mathrm{M}$ \\
\hline
\end{tabular}

the acceleration responses of SHM with optimization are lower than both PHM and SHM without optimization. Besides, the weighted RMS acceleration responses in Table 1 also show that the weighted RMS values of the vertical driver's seat, cab's pitch, and roll vibrations of SHM with optimization are strongly reduced by $34.99 \%, 42.56 \%$, and $41.72 \%$ in comparison with PHM, respectively. The above analysis results indicate that when the vehicle travels on the deformable terrain, the driver's ride comfort can be clearly improved by SHM with optimization in both the time and the low-frequency region. Therefore, the SHM with optimization could provide the best ride comfort performance for the off-road vibratory roller in the condition of the vehicle traveling.

4.3. Control Performance When the Vehicle Moves and Compacts on the Elastoplastic Soil Ground. In the working condition of the vibratory roller, the effect of the elastoplastic soil grounds on the performance of the compaction process was studied under the excitation frequencies of the drum in a range of $0.1-70 \mathrm{~Hz}[2-4,9]$; the research results showed that comprehensive drum/soil contact and loss of contact data had appeared over a range of $15-40 \mathrm{~Hz}$ [4], especially at the excitation frequencies of $28.5 \mathrm{~Hz}$ and $33 \mathrm{~Hz}$ of the drum which yielded the maximum compaction forces due to "double-jump" of the drum [2,9]. Based on the design parameters of a single drum vibratory roller [1], the excitation frequency of the vibratory drum in the working condition was also given at 28 and $35 \mathrm{~Hz}$; therefore, the excitation frequencies of the vibratory drum at 28 and $35 \mathrm{~Hz}$ with the parameters of the vehicle [1] are used for simulation. Besides, in compression process of the drum, the elastoplastic soil properties are changed during the interaction between the rigid drum and soil ground. The elastoplastic soil properties are represented via three different values of the plasticity parameter $\varepsilon$, including low-density soil $\varepsilon=0.34$, mediumdensity soil $\varepsilon=0.72$, and high-density soil $\varepsilon=0.87$ [9]. However, the elastoplastic property of low-density soil $(\varepsilon=0.34)$ is similar to the property of a soft soil deformation which is simulated in the condition of the vehicle traveling. Therefore, in order to evaluate the low-frequency performance of SHM in the condition of the vehicle working, the vehicle is moved and compacted at very slow speed $0.83 \mathrm{~m} \cdot \mathrm{s}^{-1}$ under a low/high excitation frequency, $28 / 35 \mathrm{~Hz}$, of the vibratory drum on a high elastoplastic soil ground. The 


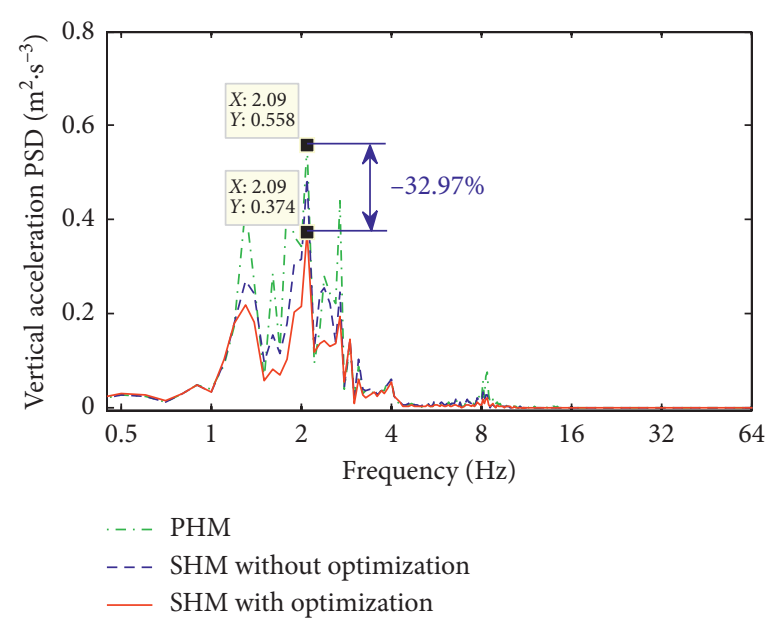

(a)

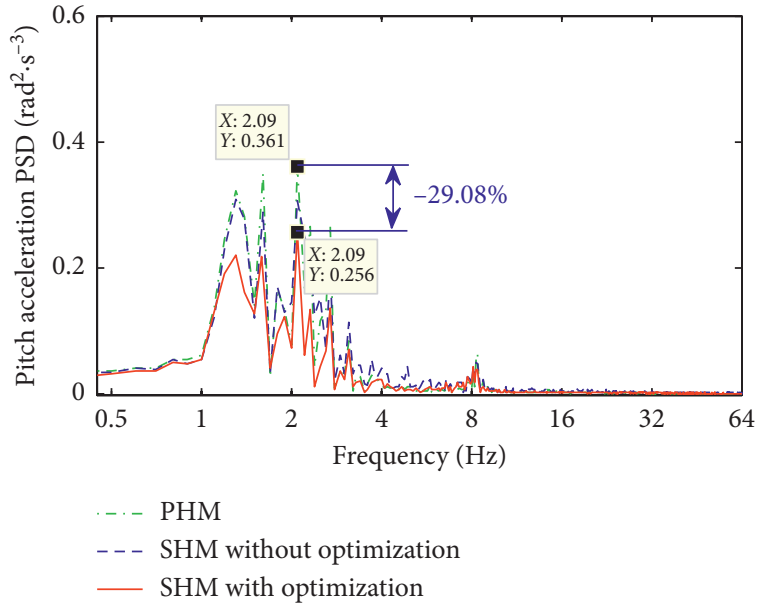

(b)

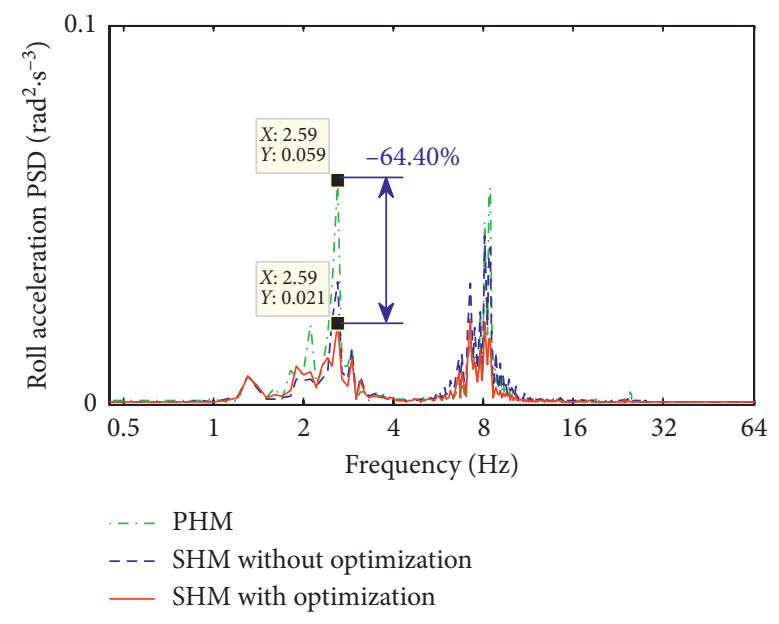

(c)

FIGURE 8: Results of the PSD acceleration responses on the deformable terrain. (a) Vertical driver's seat. (b) Cab's pitch angle. (c) Cab's roll angle.

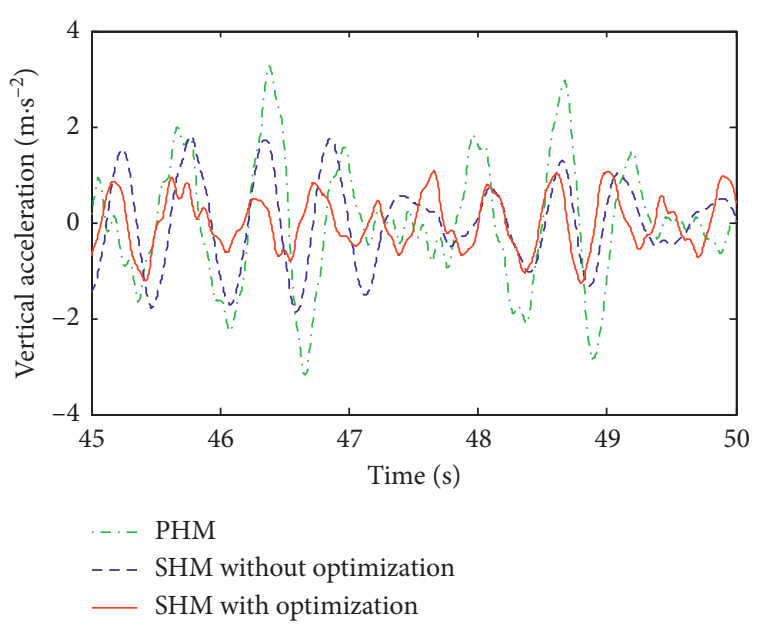

(a)

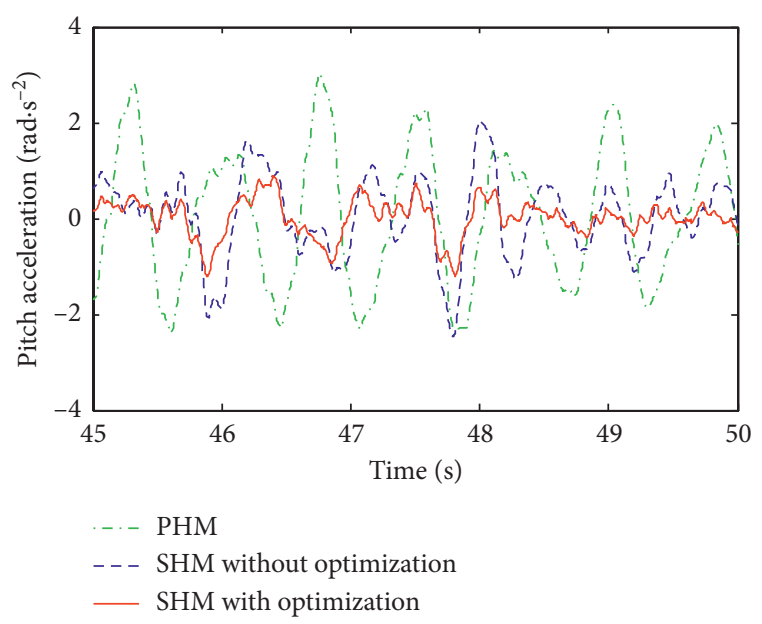

(b)

Figure 9: Continued. 


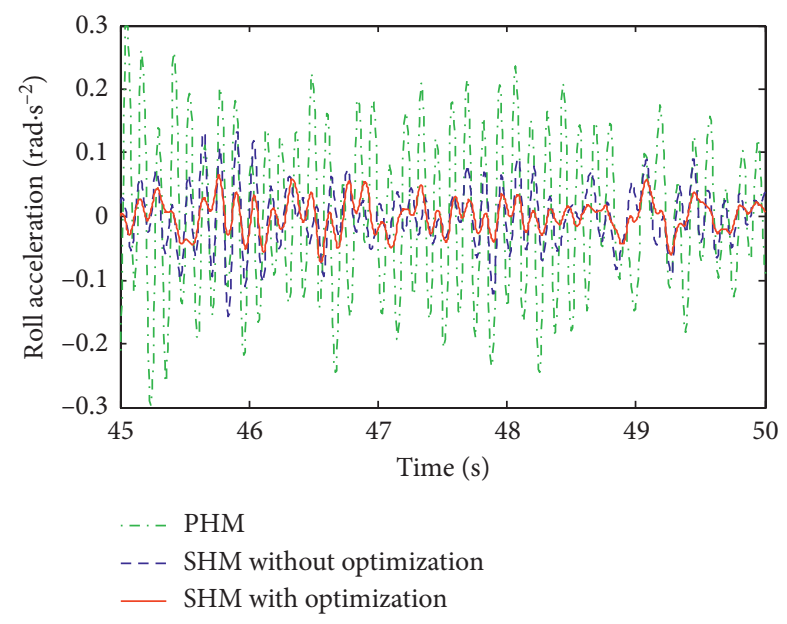

(c)

FiguRE 9: Results of the acceleration responses on the deformable terrain. (a) Vertical driver's seat. (b) Cab's pitch angle. (c) Cab's roll angle.

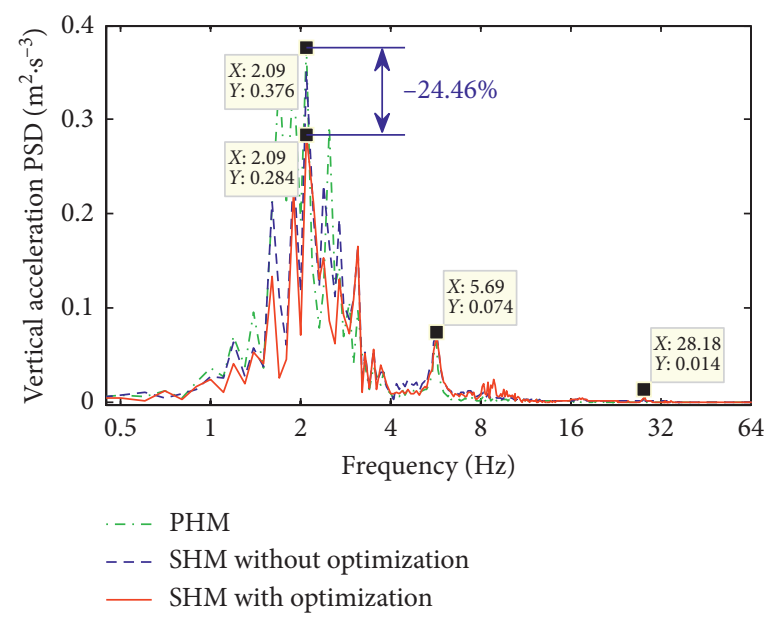

(a)

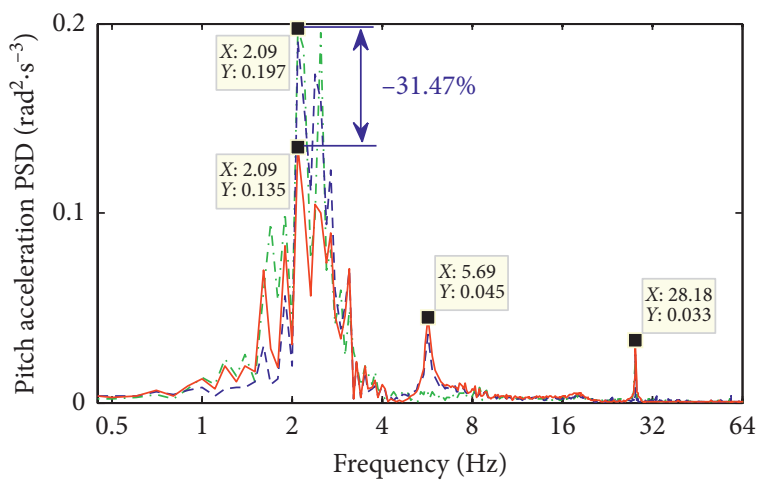

-.. PHM

- - - SHM without optimization

_ SHM with optimization

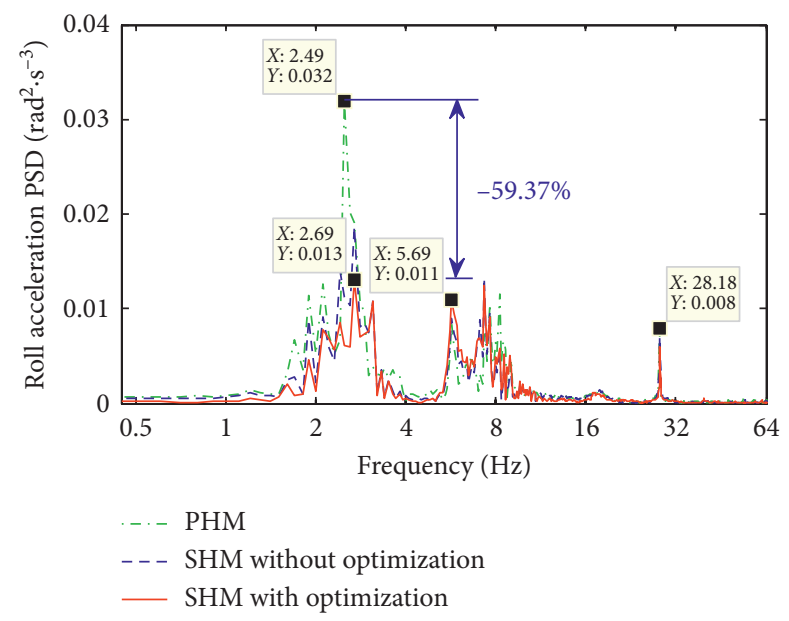

(c)

FIGURE 10: Results of the PSD acceleration responses under a low excitation frequency, $28 \mathrm{~Hz}$, of the drum. (a) Vertical driver's seat. (b) Cab's pitch angle. (c) Cab's roll angle. 


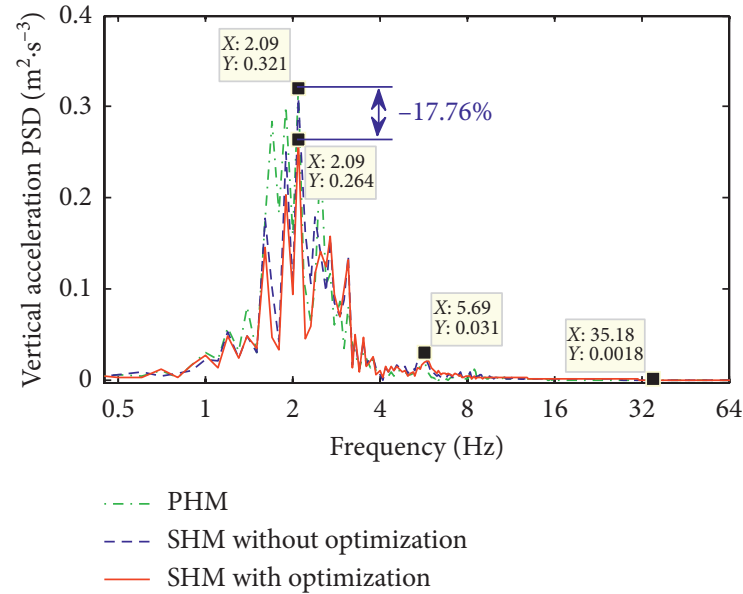

(a)

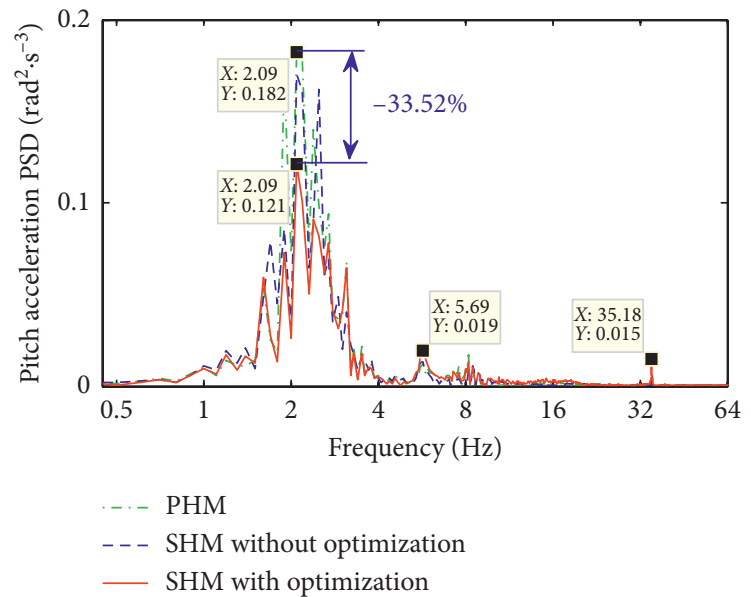

(b)

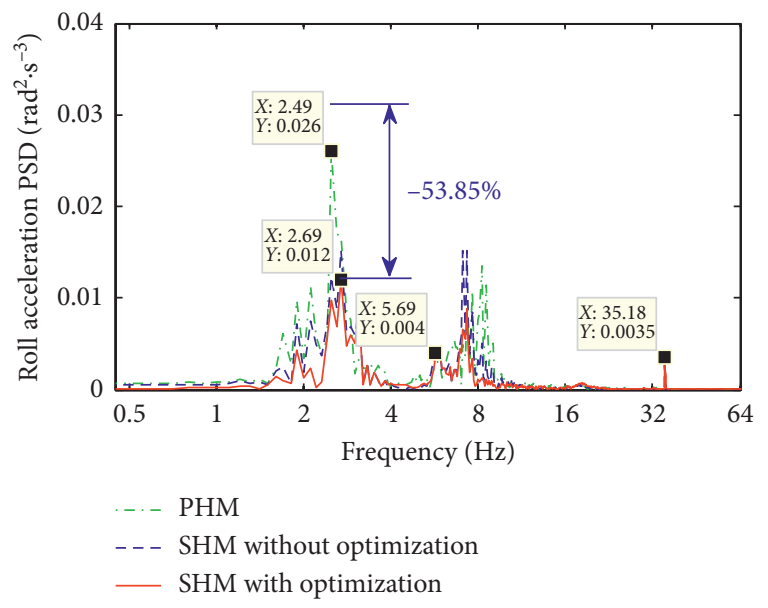

(c)

FIGURE 11: Results of the PSD acceleration responses under a high excitation frequency, $35 \mathrm{~Hz}$, of the drum. (a) Vertical driver's seat. (b) Cab's pitch angle. (c) Cab's roll angle.

parameters of the high elastoplastic soil ground includes $\varepsilon=0.87, \quad k_{\mathrm{sp}}=283 \times 10^{6} \mathrm{~N} \cdot \mathrm{m}^{-1}, \quad k_{\mathrm{se}}=42.3 \times 10^{6} \mathrm{~N} \cdot \mathrm{m}^{-1}$, and $c_{\mathrm{se}}=37.1 \times 10^{3} \mathrm{Ns} \cdot \mathrm{m}^{-1}$.

The comparison results of the PSD acceleration responses of the vertical driver's seat, cab's pitch, and roll vibrations with the cab's isolation systems at a low/high excitation frequency, $28 / 35 \mathrm{~Hz}$, of the vibratory drum are seen in Figures 10 and 11. Similarly, in the condition of the vehicle traveling, the resonance frequencies of PSD acceleration responses of the vertical driver's seat, cab's pitch, and roll vibrations of SHM without optimization and SHM with optimization are also unchanged in comparison with PHM. The simulation results also show that the resonance frequencies of SHM without optimization and SHM with optimization also occur at 28.18/ $35.18 \mathrm{~Hz}$ comparable with PHM in all three directions. This can be due to the effect of the resonance at a low/high excitation frequency, $28 / 35 \mathrm{~Hz}$, of the vibratory drum. In addition, the resonance frequency of the acceleration PSD responses of all cab's isolation systems clearly appears at $5.69 \mathrm{~Hz}$ in both graphs of Figures 10 and 11, whereas this resonance frequency does not occur in the graph of Figure 8.
This particularity may be due to the effect of the soil stiffness with the high-density soil ground.

Besides, at a low-frequency range below $4 \mathrm{~Hz}$, the maximum resonance peaks of the PSD acceleration responses of the vertical driver's seat, cab's pitch, and roll vibrations of SHM with optimization are strongly reduced in comparison with PHM by $24.46 \%, 31.47 \%$, and $59.37 \%$ at a low excitation frequency, $28 \mathrm{~Hz}$, of the drum and by $17.76 \%$, $33.52 \%$, and $53.85 \%$ at a high excitation frequency, $35 \mathrm{~Hz}$, of the drum, respectively. This is also due to the main impact of the semi-active damping force of hydraulic mount $f_{\mathrm{d}}=c_{\mathrm{h}}|\dot{z}| \dot{z}+u$. Contrarily, at a frequency range upper $4 \mathrm{~Hz}$, the PSD acceleration responses of the vertical driver's seat, cab's pitch, and roll vibrations of SHM without optimization and SHM with optimization are slightly increased in comparison with PHM, especially at the resonance frequency of $5.69 \mathrm{~Hz}$. However, the PSD acceleration values are very small. Therefore, the driver's health can be clearly improved by using SHM with optimization in the lowfrequency region when the vehicle moves and compacts on an elastoplastic soil ground. 


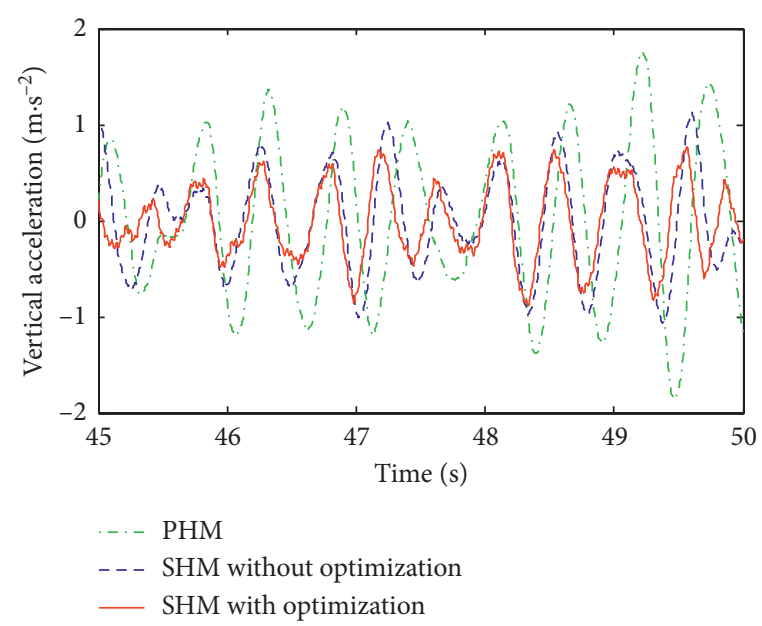

(a)

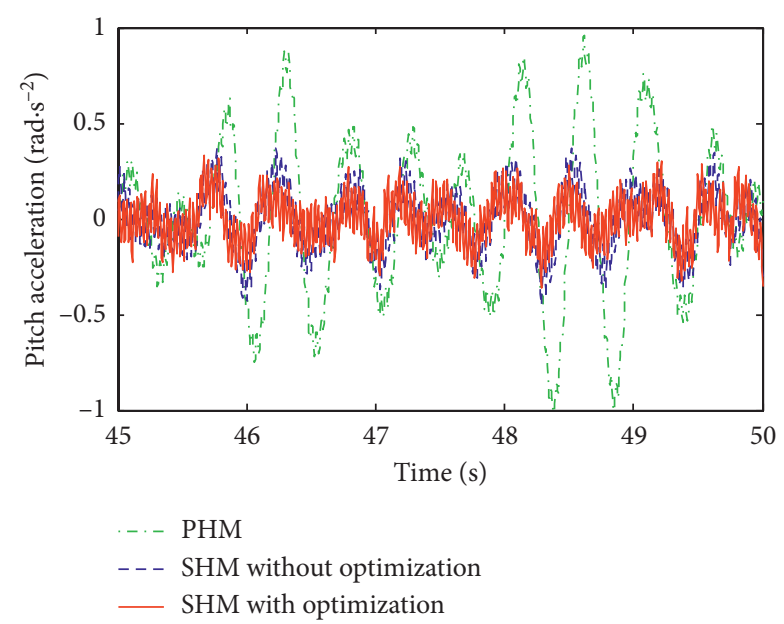

(b)

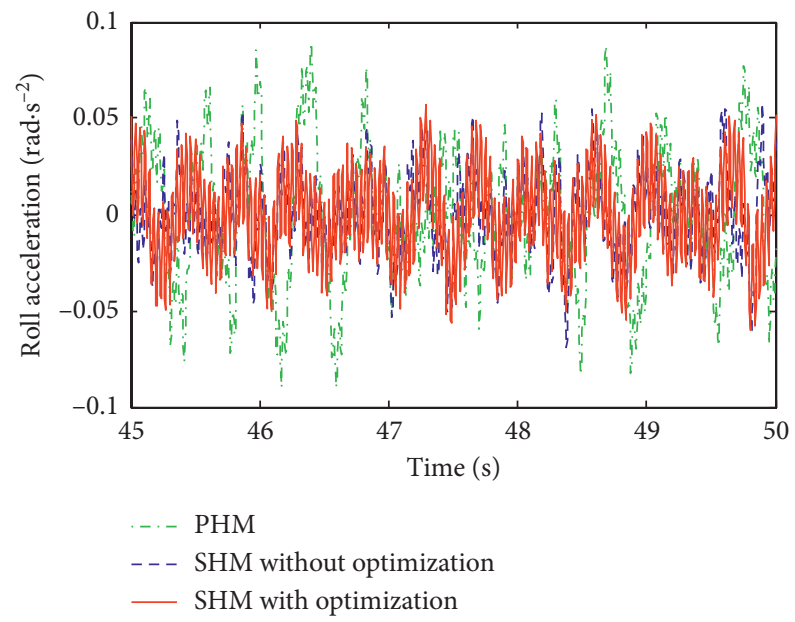

(c)

FIgURE 12: Results of the acceleration responses under a low excitation frequency, $28 \mathrm{~Hz}$, of the drum. (a) Vertical driver's seat. (b) Cab's pitch angle. (c) Cab's roll angle.

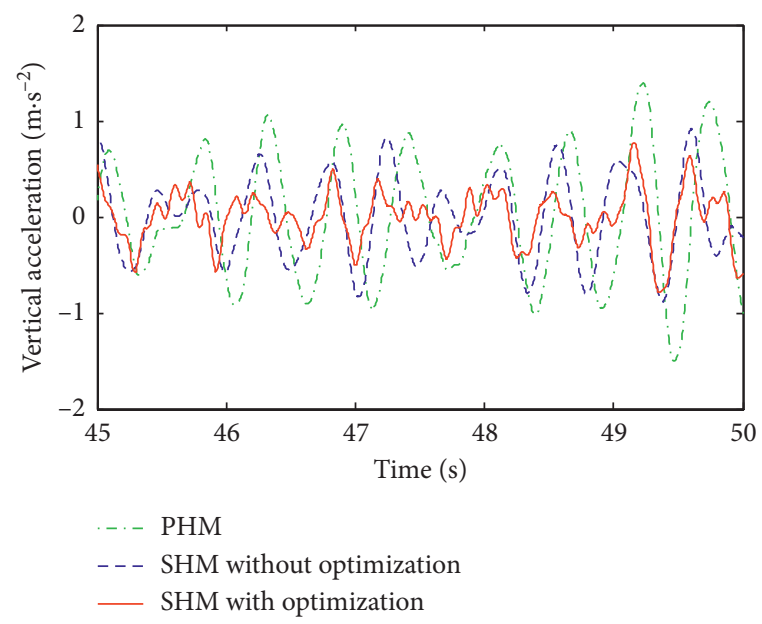

(a)

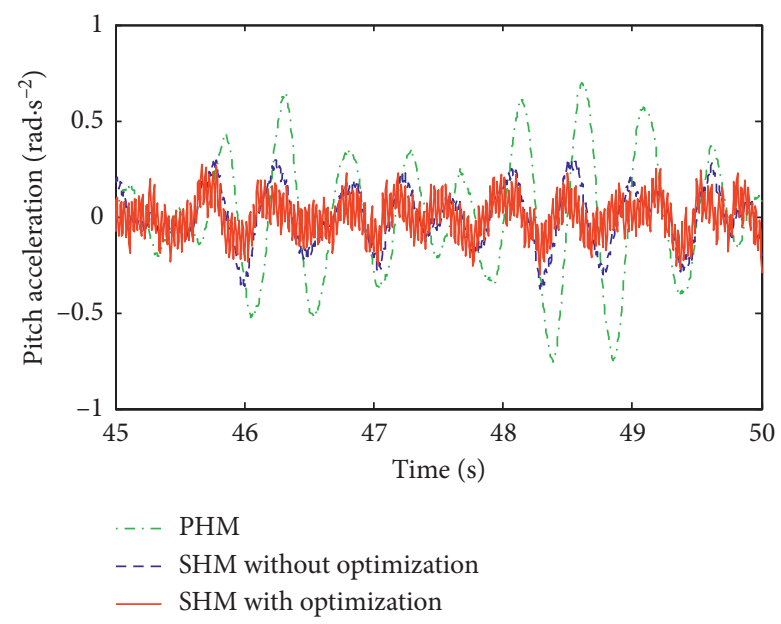

(b)

FIgURE 13: Continued. 


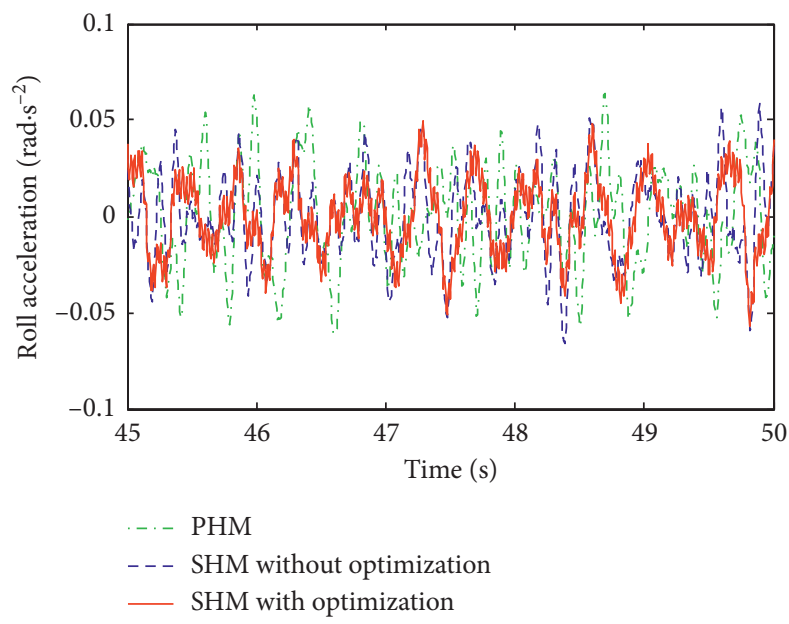

(c)

Figure 13: Results of the acceleration responses under a high excitation frequency, $35 \mathrm{~Hz}$, of the drum. (a) Vertical driver's seat. (b) Cab's pitch angle. (c) Cab's roll angle.

TABLE 3: The weighted RMS values under a low excitation frequency, $28 \mathrm{~Hz}$, of the drum.

\begin{tabular}{lcccc}
\hline Performance & PHM & SHM without optimization & SHM with optimization & SHM with optimization versus PHM (\%) \\
\hline$a_{\mathrm{wzs}}\left(\mathrm{m} \cdot \mathrm{s}^{-2}\right)$ & 0.657 & 0.501 & 0.426 & 35.16 \\
$a_{\mathrm{w} \phi \mathrm{c}}\left(\mathrm{rad} \cdot \mathrm{s}^{-2}\right)$ & 0.323 & 0.184 & 0.167 & 48.29 \\
$a_{\mathrm{w} \theta \mathrm{c}}\left(\mathrm{rad} \cdot \mathrm{s}^{-2}\right)$ & 0.085 & 0.056 & 0.053 & 37.65 \\
\hline
\end{tabular}

TABLE 4: The weighted RMS values under a high excitation frequency, $35 \mathrm{~Hz}$, of the drum.

\begin{tabular}{lcccc}
\hline Performance & PHM & SHM without optimization & SHM with optimization & SHM with optimization versus PHM (\%) \\
\hline$a_{\mathrm{wzs}}\left(\mathrm{m} \cdot \mathrm{s}^{-2}\right)$ & 0.512 & 0.453 & 0.385 & 24.80 \\
$a_{\mathrm{w} \phi \mathrm{c}}\left(\mathrm{rad} \cdot \mathrm{s}^{-2}\right)$ & 0.241 & 0.162 & 0.137 & 43.15 \\
$a_{\mathrm{w} \theta \mathrm{c}}\left(\mathrm{rad} \cdot \mathrm{s}^{-2}\right)$ & 0.061 & 0.040 & 0.039 & 36.06 \\
\hline
\end{tabular}

The simulation results in Figures 12 and 13 also show that the acceleration responses of the vertical driver's seat, cab's pitch, and roll vibrations of SHM with optimization are lower than both PHM and SHM without optimization. Besides, the values of the weighted RMS acceleration responses are also listed in Tables 3 and 4 . The weighted RMS values of the vertical driver's seat, cab's pitch, and roll vibrations of SHM with optimization are greatly reduced in comparison with SHM by $35.16 \%, 48.29 \%$, and $37.65 \%$ under a low excitation frequency, $28 \mathrm{~Hz}$, of the drum and by $24.80 \%, 43.15 \%$, and $36.06 \%$ under a high excitation frequency, $35 \mathrm{~Hz}$, of the drum, respectively. Consequently, the above analysis results also indicate that the driver's ride comfort and health are strongly improved by SHM with optimization when the vehicle moves and compacts on the high elastoplastic soil ground under both the low/high excitation frequency, $28 / 35 \mathrm{~Hz}$, of the vibratory drum.

\section{Conclusions}

Modeling and low-frequency performance analysis of semiactive cab's hydraulic mounts of the off-road vibratory roller are addressed in this work. The comparison between the simulation and test results of passive cab's isolation mounts is also carried out. The low-frequency performance of SHM using the optimal fuzzy-PID controller is then evaluated through the PSD acceleration and weighted RMS values of the vertical driver's seat, cab's pitch, and roll vibrations in both the frequency and time domains. The results are summarized as follows:

(1) In the condition of the vehicle traveling, the weighted RMS acceleration responses and the PSD acceleration responses of the vertical driver's seat, cab's pitch, and roll vibrations of SHM with optimization are lower than both PHM and SHM without optimization. Particularly, the weighted RMS values of SHM with optimization are strongly reduced in comparison with $\mathrm{PHM}$ by $34.99 \%, 42.56 \%$, and $41.72 \%$, respectively.

(2) In condition of the vehicle working, both PSD acceleration responses and the weighted RMS values of the vertical driver's seat, cab's pitch, and roll vibrations of SHM using the optimal fuzzy-PID controller are clearly smaller comparable with both PHM and SHM without optimization under both low/high excitation frequency, $28 / 35 \mathrm{~Hz}$, of the drum on the high elastoplastic soil ground. Especially, the maximum PSD values of the vertical driver's seat, cab's 
pitch, and roll vibrations of SHM with optimization are strongly reduced by $24.46 \%, 31.47 \%$, and $59.37 \%$ in comparison with PHM when the vehicle compacts at a low excitation frequency, $28 \mathrm{~Hz}$, of the drum.

(3) The above analysis results indicate that the lowfrequency and high-stiffness characteristics of SHM using the optimal fuzzy-PID controller have the best effect on isolating low-frequency vibration transmitted and controlling the cab shaking under various operating conditions of the off-road vibratory roller.

\section{Data Availability}

The data used to support the findings of this study are available from the corresponding author upon request.

\section{Conflicts of Interest}

The authors declare that there are no conflicts of interest regarding the publication of this paper.

\section{References}

[1] V. Liem, J. Zhang, V. Quynh, and R. Jiao, "Vibration analysis and modeling of an off-road vibratory roller equipped with three different cab's isolation mounts," Shock and Vibration, vol. 2018, Article ID 8527574, 17 pages, 2018.

[2] D. Adam and F. Kopf, "Theoretical analysis of dynamically loaded soils," in Proceedings of the European Workshop Compaction of Soils and Granular Materials, pp. 207-217, Paris, France, 2000.

[3] J. Li, Z. Zhang, H. Xu, and Z. Feng, "Dynamic characteristics of the vibratory roller test-bed vibration isolation system: simulation and experiment," Journal of Terramechanics, vol. 56, pp. 139-156, 2014.

[4] J. Paul and A. Michael, "Capturing nonlinear vibratory roller compactor behavior through lumped parameter modeling," Journal of Engineering Mechanics, vol. 134, no. 8, pp. 684-693, 2008.

[5] X. Zhang, Modelling, simulation and optimization of ride comfort for off road articulated dump trucks, Ph.D. thesis, Southeast University, Nanjing, China, 2010.

[6] A. Pakowski and D. Cao, "Effect of soil deformability on offroad vehicle ride dynamics," SAE International Journal of Commercial Vehicles, vol. 6, no. 2, pp. 362-371, 2013.

[7] R. A. Irani, R. J. Bauer, and A. Warkentin, "Dynamic wheelsoil model for lightweight mobile robots with smooth wheels," Journal of Intelligent \& Robotic Systems, vol. 71, no. 2, pp. 179-193, 2013.

[8] S. Park, A. A. Popov, and D. J. Cole, "Influence of soil deformation on off-road heavy vehicle suspension vibration," Journal of Terramechanics, vol. 41, no. 1, pp. 41-68, 2004.

[9] A. Kordestani, S. Rakheja, P. Marcotte, A. Pazooki, and D. Juras, "Analysis of ride vibration environment of soil compactors," SAE International Journal of Commercial Vehicles, vol. 3, no. 1, pp. 259-272, 2010.

[10] V. Quynh, Vibration study and control for cab of vibratory roller, Ph.D. thesis, Southeast University, Nanjing, China, 2013.

[11] M. Griffin, Handbook of Human Vibration, Academic Press, London, UK, 1990.
[12] International Organization for Standardization, "Mechanical vibration and shock-evaluation of human exposure to whole body vibration-part 2: general requirements," Tech. Rep. ISO 2631-1:1997, ISO, Geneva, Switzerland, 1997.

[13] Ş. Yildirim, "Vibration control of suspension systems using a proposed neural network," Journal of Sound and Vibration, vol. 277, no. 4-5, pp. 1059-1069, 2004.

[14] N. Ebrahimi and A. Gharaveisi, "Optimal fuzzy supervisor controller for an active suspension system," International Journal of Soft Computing \& Engineering, vol. 2, no. 4, pp. 36-39, 2012.

[15] Z. Xie, P. Wong, J. Zhao, T. Xu, and I. Wong, "A noiseinsensitive semi-active air suspension for heavy-duty vehicles with an integrated fuzzy-wheelbase preview control," Mathematical Problem in Engineering, vol. 2013, Article ID 121953, 12 pages, 2013.

[16] B. Kasemi, A. G. A. Muthalif, M. M. Rashid, and S. Fathima, "Fuzzy-PID controller for semi-active vibration control using magnetorheological fluid damper," Procedia Engineering, vol. 41, pp. 1221-1227, 2012.

[17] T. Nguyen, A novel semi-active magnetorheological mount for vibration isolation, Ph.D. thesis, The University of Toledo, Toledo, OH, USA, 2009.

[18] A. Muthalif, B. Kasemi, D. Nordin, and M. Rashid, "Semiactive vibration control using experimental model of Magnetorheological damper with adaptive fuzzy-PID controller," Smart Structures and Systems, vol. 20, no. 1, pp. 85-97, 2017.

[19] S. D. Nguyen, Q. H. Nguyen, and S.-B. Choi, "A hybrid clustering based fuzzy structure for vibration control-part 2: an application to semi-active vehicle seat-suspension system," Mechanical Systems and Signal Processing, vol. 56-57, pp. 288-301, 2015.

[20] W. Wang, Y. Song, Y. Xue, H. Jin, J. Hou, and M. Zhao, “An optimal vibration control strategy for a vehicle's active suspension based on improved cultural algorithm," Applied Soft Computing, vol. 28, pp. 167-174, 2015.

[21] Y. Chen, Z. Wang, J. Qiu, and Z. Huang, "Hybrid fuzzy skyhook surface control using multi-objective microgenetic algorithm for semi-active vehicle suspension system ride comfort stability analysis," Journal of Dynamic Systems Measurement \& Control, vol. 134, no. 4, pp. 1-14, 2012.

[22] International Organization for Standardization, "Reporting vehicle road surface irregularities,” Tech. Rep. ISO/TC108/SC2/ WG4 N57, Thieme Medical Publishers, Stuttgart, Germany, 1982.

[23] M. Mitschke, Dynamik der Kraftfahrzeuge, Springer-Verlag, Berlin, Germany, 1972.

[24] M. Rahmat, "Application of selftuning fuzzy PID controller on industrial hydraulic actuator using system identification approach," International Journal on Smart Sensing \& Intelligent Systems, vol. 2, no. 2, pp. 246-261, 2009.

[25] E. H. Mamdani and S. Assilian, "An experiment in linguistic synthesis with a fuzzy logic controller," International Journal of Man-Machine Studies, vol. 7, no. 1, pp. 1-13, 1975.

[26] Z. Nariman, M. Salehpour, A. Jamali, and E. Hanghgoo, "Pareto optimization of a five-degree of freedom vehicle vibration model using a MUGA," Engineering Applications of Artificial Intelligence, vol. 23, no. 4, pp. 543-551, 2010.

[27] H. John, G. Michael, and D. Gregory, "Multi-objective control optimization for semi-active vehicle suspensions," Journal of Sound and Vibration, vol. 330, pp. 5502-5516, 2011.

[28] J. Y. Wong, "Data processing methodology in the characterization of the mechanical properties of terrain," Journal of Terramechanics, vol. 17, no. 1, pp. 13-41, 1980. 


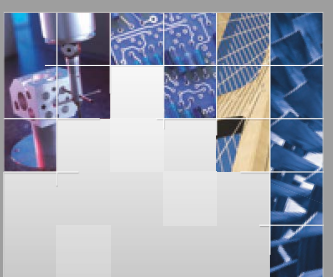

\section{Enfincering}
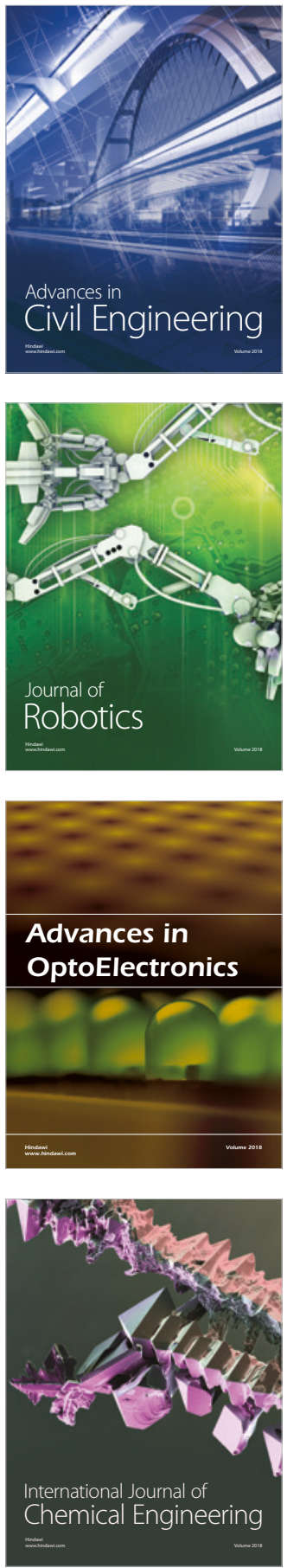

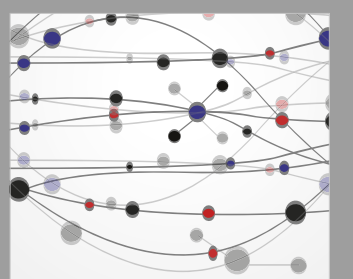

\section{Rotating \\ Machinery}

The Scientific World Journal

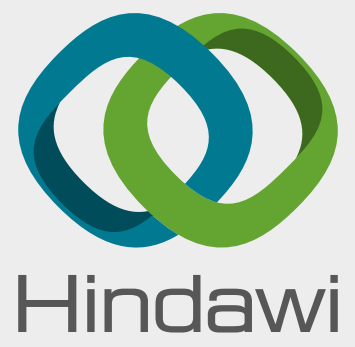

Submit your manuscripts at

www.hindawi.com
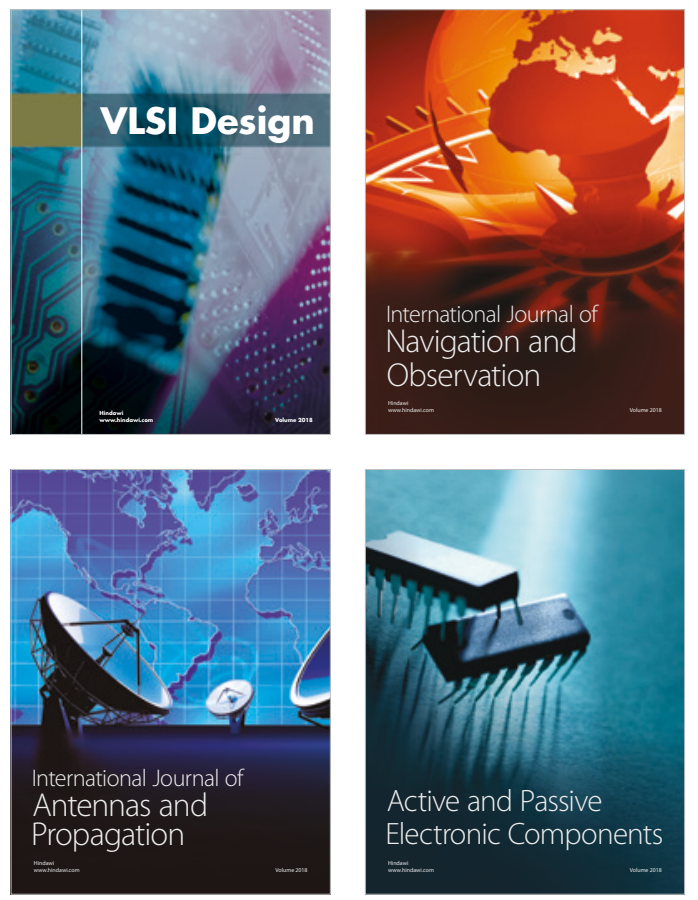
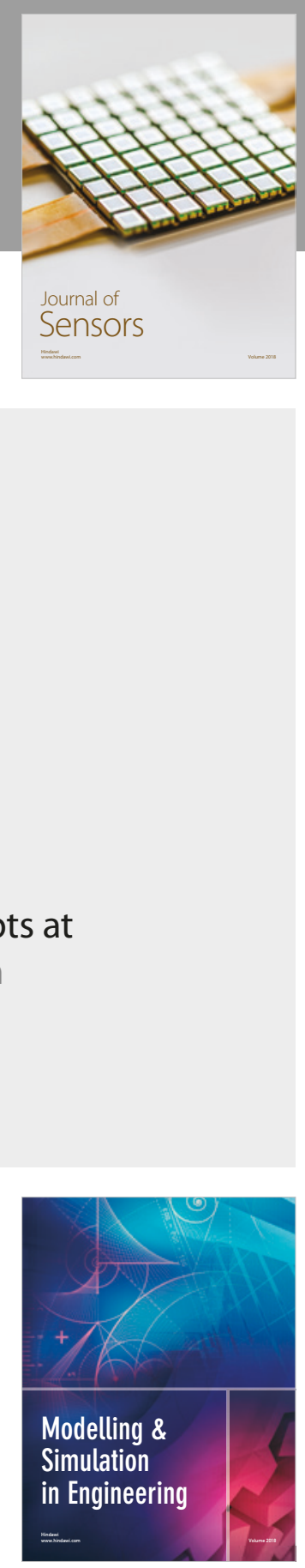

\section{Advances \\ Multimedia}
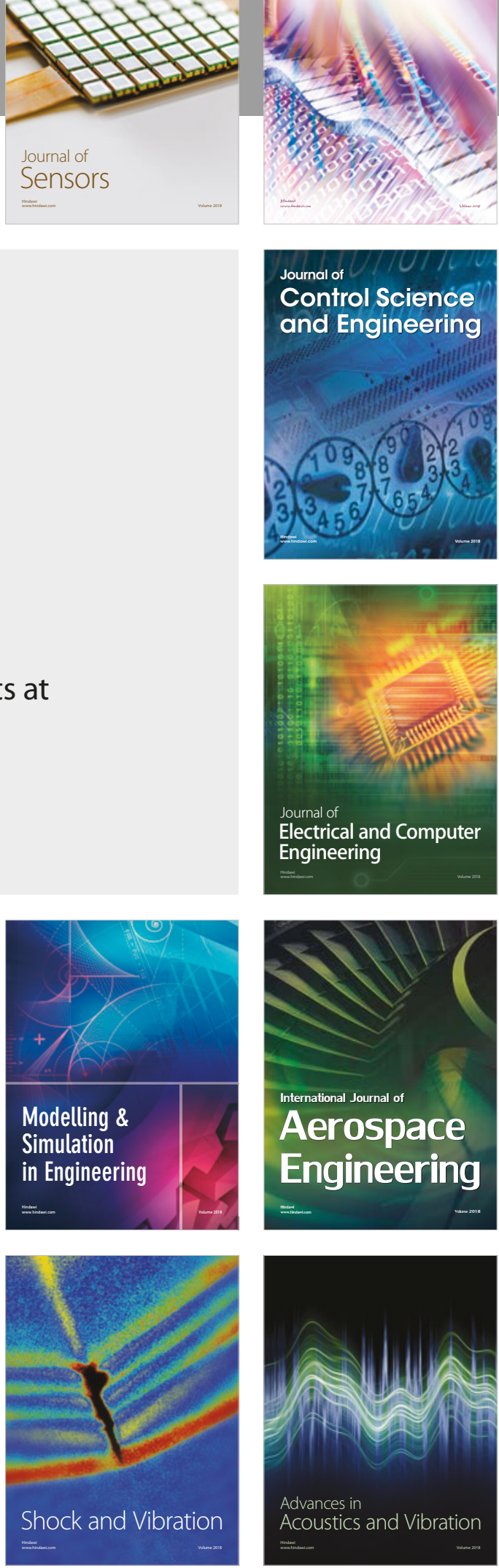